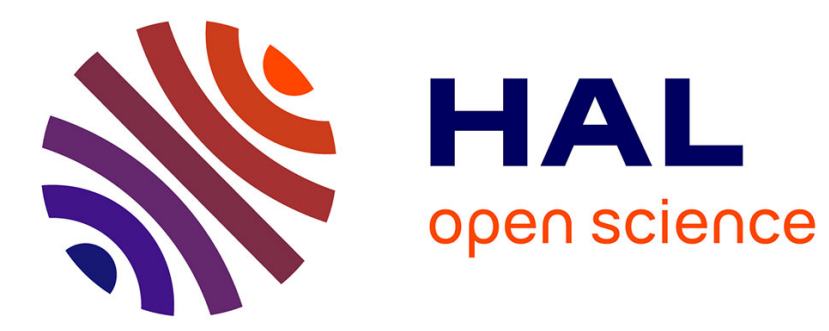

\title{
Line parameters measurements and modeling for the $\nu 6$ band of CH3F: Generation of a complete line list for atmospheric databases
}

\author{
D. Jacquemart, M. Guinet
}

\section{To cite this version:}

D. Jacquemart, M. Guinet. Line parameters measurements and modeling for the $\nu 6$ band of CH3F: Generation of a complete line list for atmospheric databases. Journal of Quantitative Spectroscopy and Radiative Transfer, 2016, 185, pp.58-69. 10.1016/j.jqsrt.2016.08.010 . hal-01375439

\section{HAL Id: hal-01375439 \\ https://hal.sorbonne-universite.fr/hal-01375439}

Submitted on 3 Oct 2016

HAL is a multi-disciplinary open access archive for the deposit and dissemination of scientific research documents, whether they are published or not. The documents may come from teaching and research institutions in France or abroad, or from public or private research centers.
L'archive ouverte pluridisciplinaire HAL, est destinée au dépôt et à la diffusion de documents scientifiques de niveau recherche, publiés ou non, émanant des établissements d'enseignement et de recherche français ou étrangers, des laboratoires publics ou privés. 


\title{
Line parameters measurements and modeling for the $v_{6}$ band of $\mathrm{CH}_{3} \mathrm{~F}$ : generation of a complete line list for atmospheric databases
}

\author{
D. Jacquemart ${ }^{a}$, M. Guinet ${ }^{a}$ \\ ${ }^{a}$ Sorbonne Universités, UPMC Univ Paris 06, CNRS, UMR 8233, MONARIS, Université \\ Pierre et Marie Curie, 4 place Jussieu, F-75005, Paris, France
}

Number of Figures: 11

Number of Tables: 5

Supplementary materials (electronic files): 2

Please send proofs to: David Jacquemart

Email: david.jacquemart@upmc.fr

Keywords : methyl fluoride; $v_{6}$ band; line intensities; self-broadening coefficients; $J$ and $K$ dependences. 


\begin{abstract}
The $8.5 \mu \mathrm{m}$-spectral region of methyl fluoride was studied in terms of line positions, intensities and self-broadening coefficients at room temperature. A multispectrum fitting was used to retrieve from 7 high-resolution Fourier transform spectra line parameters for 787 transitions belonging to the $v_{6}$ band between 1078 and $1240 \mathrm{~cm}^{-1}$. The accuracy of line intensities and widths measurements were estimated to be around 5\% and 5-10\% respectively. $J$ - and $K$-rotational dependences of the transition dipole moment squared and the selfbroadening coefficients were observed and modeled from the measurements. A complete line list of almost 1500 transitions was generated for atmospheric or industrial detection of $\mathrm{CH}_{3} \mathrm{~F}$. Comparisons with previous studies from the literature were also performed.
\end{abstract}




\section{Introduction}

A recent effort has been made by our group to characterize spectral-absorption regions of $\mathrm{CH}_{3} \mathrm{X}$ gases: $\mathrm{CH}_{3} \mathrm{Br}$ around $7 \mu \mathrm{m}$ [1] and $10 \mu \mathrm{m}$ [2-7], $\mathrm{CH}_{3} \mathrm{Cl}$ around $3 \mu \mathrm{m}$ [8-11] and 6.9 $\mu \mathrm{m}$ [12-13]. The line positions [1,2,8,12], intensities [1,2,8,12], room-temperature self- and $\mathrm{N}_{2}$-broadening coefficients $[2,7,9,10,13]$, temperature exponent $[4,7,13]$, and line mixing effects $[3,5,11]$ have been studied for these two molecules in order to generate complete line list for atmospheric applications. Most of these spectroscopic data have been included in the recent HITRAN [14] and GEISA [15] databases.

The present work concerns methyl fluoride spectrum around $8.5 \mu \mathrm{m}$ where the $v_{6}$ band absorbs closely to the strong $v_{3}$ band at $9.5 \mu \mathrm{m}$. Concerning the weaker $v_{6}$ band, previous spectroscopic studies have already been performed: one can cite the works of Papoušek et al. [16,17] for line positions and interactions between states, and the work of Lepère et al. [18] for the measurements of line intensities using tunable diode laser spectrometer. Concerning self-broadening coefficients, measurements have been performed in Ref. [18] for 13 transitions of the $v_{6}$ band. One can also notice the works of Lerot et al. [19,20], Lepère et al. [21], Lance et al. [22] and Guerin et al. [23] for the self-, $\mathrm{N}_{2^{-}}, \mathrm{O}_{2^{-}}$, and air-widths and their temperature dependences $[19,20]$ for transitions of the $v_{2}$ and $v_{5}$ bands.

In this work, a line list has first been generated using from the literature positions and assignments [24], intensities [18], and energy of the lower state of the transition [25]. Then, a global analysis using multispectrum fitting procedure has been performed on seven experimental spectra recorded with various pressures and previously calibrated in wavenumbers. The results have been analyzed and compared to the literature for finally generating for the $v_{6}$ band of ${ }^{12} \mathrm{CH}_{3} \mathrm{~F}$ a complete line list of positions, intensities and selfbroadening coefficients. Most of the spectroscopic data published in the literature for the $v_{6}$ band of $\mathrm{CH}_{3} \mathrm{~F}$ have been confirmed and improved especially for line intensities and selfbroadening coefficients.

This study has been performed as a continuation of our previous works on $\mathrm{CH}_{3} \mathrm{X}$ molecules [1-13]. Note that semi-empirical models have been used both in the previous works as in the present one to analyze the rotational dependence of transition dipole moments squared (Herman-Wallis factors depending on $J$ and $K$ ) and the broadening coefficients $(K$ rotational modeling $\gamma_{J}(K)=a_{J}^{0}+a_{J}^{2} K^{2}$ for each set of measurements with same $J$ value).

The experimental conditions are first presented in Section 2. Section 3 is dedicated to the measurements, their analysis and comparisons to literature for line positions, intensities, 
and self broadening coefficients respectively. Finally, the generation of various line lists will be described in Section 4.

\section{Experimental spectra}

Eight Fourier transform spectra have been recorded at room temperature using the Bruker IFS $120 \mathrm{HR}$ interferometer of the MONARIS. The experimental conditions are summarized in Table 1.

(Table 1)

The interferometer was equipped with a $\mathrm{KBr}$ beam splitter, a MCT photovoltaic detector, and a Globar source. A $(68.8 \pm 0.1) \mathrm{cm}$ path length cell has been used to record all spectra. For all of them (except spectrum 8, see Table 1) an optical filter covering the 860$1320 \mathrm{~cm}^{-1}$ spectral region has been used. The cell was equipped with $\mathrm{KBr}$ windows. The overview of the $\mathrm{CH}_{3} \mathrm{~F}$ absorption region in spectrum 5 is presented in Fig. 1 between 950 and $1250 \mathrm{~cm}^{-1}$. The $v_{3}$ band is saturated under experimental conditions of this work but the focus of the present study is the weaker $v_{6}$ band. Figure 2 illustrates the structure of the $R^{Q}$ subbranches between 1180 and $1240 \mathrm{~cm}^{-1}$. Note that the first letter refers to the $K$ variation ( $R$ for $\Delta K=1)$, the second one in upper case corresponds to the $J$ variation ( $Q$ for $\Delta J=0)$. The subbranch noted $R_{0}^{Q}$ refers to various $R_{0}^{Q}(J)$ transitions with $K=0$ ( $J$ and $K$ being the rotational quantum numbers of the lower state of the transition).

(Figure 1)

(Figure 2)

The commercial gas sample of methyl fluoride, furnished by Alpha Gaz, with a stated of purity of $99.0 \%$ in natural abundance was used without any purification. The pressures of $\mathrm{CH}_{3} \mathrm{~F}$ (ranging from 0.1 to 10 mbar) inside the cell have been measured with 2 baratron gauges with accuracy better than $\pm 0.15 \%$ for the 1 mbar full scale thermoregulated gauge and $\pm 0.25 \%$ for the 10 mbar full scale. Note that due to the low pressures used in this work, no attempt has been done to measure self-shifting parameters. The temperature of the gas sample has been measured with accuracy equal to $\pm 0.1 \mathrm{~K}$ using platinum probes inside the cell. 
The first seven spectra of Table 1 have been recorded with optical filter covering the 800-1300 $\mathrm{cm}^{-1}$ spectral region. For spectrum 8, recorded with no optical filter from 800 to $4000 \mathrm{~cm}^{-1}$, the observed $\mathrm{CO}_{2}$ transitions near $2300 \mathrm{~cm}^{-1}$ and $\mathrm{H}_{2} \mathrm{O}$ transitions near 1900 and $3700 \mathrm{~cm}^{-1}$ (present as impurities in the tank of the interferometer) allowed to perform an accurate wavenumber calibration (see Section 3.1).

The average interferograms have been Fourier transformed using the procedure included in the Bruker software OPUS package, selecting a Mertz phase error correction. The spectra have not been numerically apodized. An average signal-to-noise ratio (peak to peak) between 150 and 200 has been obtained for the various experimental spectra of Table 1. Note that a weak multiplicative channel, due to the cell windows, was observed in all recorded spectra with maximum peak-to-peak amplitude about 2\% (see Fig. 2). The period of the channel (about $2.2 \mathrm{~cm}^{-1}$ ) being larger than the adjusted spectral domains (from 0.1 to 0.2 $\mathrm{cm}^{-1}$ ), the multiplicative channel can be taken into account with a linear background.

\section{Measurements, analysis and comparisons with literature}

A multispectrum fitting procedure [26] has been applied to adjust simultaneously 7 experimental (spectra 1-7, see Table 1 for experimental conditions) of $\mathrm{CH}_{3} \mathrm{~F}$, constraining the adjustment of a transition by using the same set of line parameters for the calculation of this transition in every spectra. As a final result the line position, the line intensity and the self broadening coefficient have been retrieved for 787 transitions of the $v_{6}$ band of ${ }^{12} \mathrm{CH}_{3} \mathrm{~F}$. The broadening coefficients of ${ }^{12} \mathrm{CH}_{3} \mathrm{~F}$ transitions by ${ }^{13} \mathrm{CH}_{3} \mathrm{~F}$ have been considered equal to the self-broadening coefficients of ${ }^{12} \mathrm{CH}_{3} \mathrm{~F}$. An example of the multispectrum fitting procedure for a spectral range containing 3 transitions is presented in Fig. 3. A Voigt profile has been used without observing any significant signatures in the residuals of the fit. One can observe the well reproduced wings of the sinus cardinal apparatus function. For each spectrum, the apparatus function $f(\sigma)$ has been calculated performing numerically the Fourier transform of the optical weighting of the interferograms, taking into account the finite optical path difference $\Delta_{\max }$ and the optical weighting due do the size of the beam inside the interferometer (finite entrance beam with a beam radius $R$ and a focal distance $f$ ).

$$
f(\sigma)=T F\left[\Pi_{\Delta_{\max }}(\Delta) \cdot P_{o p t}(\Delta)\right],
$$


where

$$
\Pi_{\Delta_{\max }}(\Delta)=1 \text { for } 0 \leq \Delta \leq \Delta_{\max },
$$

$$
\Pi_{\Delta_{\max }}(\Delta)=0 \text { for } \Delta>\Delta_{\max }
$$

and

$$
P_{o p t}(\Delta)=\left|\sin c\left(\frac{\sigma_{0} \Omega \Delta}{2}\right)\right| \text {, with } \Omega=\pi \frac{R^{2}}{f^{2}} .
$$

(Figure 3)

Measurements, analysis and comparisons with literature performed in this work for line positions, intensities and self-broadening coefficients will be presented in the next subsections.

\subsection{Line positions}

Concerning the wavenumbers calibration, absolute wavenumbers from HITRAN 2012 [27] have been used for 36 transitions of the $v_{3}$ band of $\mathrm{CO}_{2}$ near $2300 \mathrm{~cm}^{-1}, 80$ and 87 transitions of $\mathrm{H}_{2} \mathrm{O}$ around $1700 \mathrm{~cm}^{-1}$ ( $v_{2}$ band) and $3700 \mathrm{~cm}^{-1}$ ( $v_{1}$ and $v_{3}$ bands) respectively. The quantity $\varepsilon=\left(v_{\text {HITRAN2012 }}-v_{\text {this work }}\right) / v_{\text {HITRAN2012 has been calculated from measurements }}$ in spectrum 8, and averages values have been deduced: $\langle\varepsilon\rangle=(-3.7 \pm 0.4) \times 10^{-7}$, $(-3.0 \pm 0.2) \times 10^{-7},(-2.7 \pm 0.4) \times 10^{-7}$ for $\mathrm{CO}_{2}$ near $2300 \mathrm{~cm}^{-1}, \mathrm{H}_{2} \mathrm{O}$ near $1700 \mathrm{~cm}^{-1}$ and 3700 $\mathrm{cm}^{-1}$ respectively. Note that using the 2008 edition of HITRAN [14] for the $v_{3}$ band of $\mathrm{CO}_{2}$ the average value becomes $\langle\varepsilon\rangle=(-3.3 \pm 0.4) \times 10^{-7}$ closer to the other values. In HITRAN 2012, the line positions measurements by Miller and Brown [28] have been replaced by the calculated line positions from CDSD database [29]. The average value of $(-3.0 \pm 0.5) \times 10^{-7}$ has been retained for the wavenumber calibration factor $\varepsilon$. It corresponds to a deviation of $-0.3 \times 10^{-3} \mathrm{~cm}^{-1}$ at $1000 \mathrm{~cm}^{-1}$ with a precision of $0.05 \times 10^{-3} \mathrm{~cm}^{-1}$. Taking into account the accuracy of $\mathrm{H}_{2} \mathrm{O}$ and $\mathrm{CO}_{2}$ line positions in HITRAN2012 [27] and the precision on the wavenumbers calibration, the accuracy on line positions measurements has been estimated between $0.1 \times 10^{-3}$ and $1 \times 10^{-3} \mathrm{~cm}^{-1}$.

A comparison of our measured line positions with the calculated positions from $\mathrm{P}$. Pracna [24] is presented in Fig. 4. By plotting this comparison versus line intensity, it can be observed that the discrepancies between this work and Ref. [24] are increasing for weak transitions, showing the difficulty to perform accurate measurements for weak transitions. The average difference $\left\langle\sigma_{\text {obs }}-\sigma_{\text {Ref. [24] }}\right\rangle=-(0.02 \pm 0.24) 10^{-3} \mathrm{~cm}^{-1}$ is very good. The standard deviation is consistent with the accuracy previously estimated to be between $0.1 \times 10^{-3}$ and 
$1 \times 10^{-3} \mathrm{~cm}^{-1}$. An extract of the whole file of measurements and comparisons, available as supplementary data, is presented in Table 2.

(Figure 4)

Note that for most of the transitions with $K$ that are multiple of 3 (except $K=0$ ), 2 components (A1 and A2) exist but are totally blended. However, in the case of the $P^{P}{ }_{3}, P^{R}$ and $P_{3}^{Q}$ sub-branches, the two components begin to split when $J$ is increasing. This has been clearly observed and measured for $P^{P}{ }_{3}$ transitions when $J$ is greater than 20 or for $P_{3}^{Q}$ transitions when $J$ is greater than 17 (see Table 2). Consequently, for all transitions of the $P^{P}{ }_{3}$, $P^{R}{ }_{3}$ and $P_{3}^{Q}$ sub-branches, the 2 components have been listed in Table 2 and in the final line list.

(Table 2)

As observed in Table 2 for $P_{3}^{Q}$ sub-branch, the 2 components are not resolved for $J$ values lower than 17. Then from $J=17$ to upper values, the splitting between the 2 components is increasing reaching for example $6.5 \times 10^{-3} \mathrm{~cm}^{-1}$ for $J=22$.

\subsection{Line intensities}

Line intensities $S_{\text {obs }}\left(T_{0}\right)$ in cm.molecule ${ }^{-1}$ at $296 \mathrm{~K}$ of ${ }^{12} \mathrm{CH}_{3} \mathrm{~F}$ in natural abundance $I_{a}$ (98.93\% same as the one of ${ }^{12} \mathrm{C}$ since ${ }^{19} \mathrm{~F}$ is the only natural isotope on Earth) are retrieved from the multispectrum fitting procedure. The purity of the sample (99\%) has been taken into account.

All our measured line intensities have been analyzed using the semi-empirical model based on Herman-Wallis factor. The transition dipole moment squared $R^{2}$ (in bebye ${ }^{2}$ ) has been obtained from $S_{o b s}\left(T_{0}\right)$ using following equation:

$$
S_{o b s}\left(T_{0}\right)=\frac{1}{4 \pi \varepsilon_{0}} \frac{8 \pi^{3}}{3 h c} \frac{v_{0} I_{a}}{Z_{t o t}\left(T_{0}\right)} \exp \left(-\frac{h c E^{\prime \prime}}{k_{B} T_{0}}\right)\left[1-\exp \left(-\frac{h c v_{0}}{k_{B} T_{0}}\right)\right] R^{2} g_{s},
$$

where $1 / 4 \pi \varepsilon_{0}=10^{-36} \mathrm{erg} \cdot \mathrm{cm}^{3} \cdot \mathrm{D}^{-2} ; h$ is the Planck's constant equal to $6.6260755 \times 10^{-27} \mathrm{erg} \cdot \mathrm{s}$ $\left(1 \mathrm{erg}=10^{-7} \mathrm{~J}\right) ; c$ is the vacuum velocity of light equal to $2.99792458 \times 10^{10} \mathrm{~cm} \cdot \mathrm{s}^{-1} ; v_{0}$ is the 
transition wavenumber in $\mathrm{cm}^{-1} ; Z_{t o t}\left(T_{0}\right)$ is the total partition function at temperature $T_{0}$ (calculated in Ref. [18]); $E^{\prime \prime}$ is the energy of the lower level in $\mathrm{cm}^{-1}$ from Ref. [25]; $k_{B}$ is the Boltzmann's constant equal to $1.380658 \times 10^{-16} \mathrm{erg} \cdot \mathrm{K}^{-1} ; g_{s}$ is the statistical weight due to nuclear spin of the lower level $\left(g_{s}=4\right.$, except for $K=3,6,9,12 \ldots$ where $\left.g_{s}=8\right)$.

Then, the transition dipole moment squared can be expressed as:

$$
R^{2}=R_{0}^{2} \times H(x, K, \Delta K, \Delta J) \times H L(J, K, \Delta J, \Delta K, \Delta \ell) .
$$

$R_{0}^{2}$ is the vibrational transition dipole moment squared, $H(x, K, \Delta J, \Delta K)$ is the Herman-Wallis factor, and $H L(J, K, \Delta J, \Delta K, \Delta \ell)$ is the Hönl-London factor. The Herman-Wallis factor has been expressed, as it has been done by Lepère et al. [18], using the coefficients $\alpha, \beta$ and $\gamma$ in the following expression:

$$
H=(1+\alpha x+\beta K \Delta K+\gamma x K \Delta K),
$$

where $x=-J, 0, J+1$ for the $P-, Q-, R$-branch transitions, respectively.

The following expression of $H L(J, K, \Delta J, \Delta K, \Delta \ell)$ [18] for perpendicular band has been used:

$$
\begin{gathered}
H L=(J+K \Delta K+2)(J+K \Delta K+1) / 4(J+1) \text { for } \Delta J=+1 \text { transitions, } \\
H L=(2 J+1)[J(J+1)-K(K+\Delta K)] / 4 J(J+1) \text { for } \Delta J=0 \text { transitions, } \\
H L=(J-K \Delta K-1) / 4 J \text { for } \Delta J=-1 \text { transitions. }
\end{gathered}
$$

As done in Ref. [18], for $K=0$, the Hönl-London factors have been multiplied by a factor 2 .

The transition dipole moment squared obtained for the complete set of 787 measured transitions has been used to fit the parameters $R_{0}{ }^{2}, \alpha, \beta$ and $\gamma$ of Eq. (3). The fitted parameters are given in Table 3 together with those obtained in Ref. [18]. Note that the vibrational band intensity $S_{v}^{0}$ can be easily calculated from the transition dipole moment squared using following equation from Ref. [18]:

$$
S_{v}^{0}=\left(\frac{8 \pi^{3}}{3 h c}\right) \sigma_{0} L\left(\frac{T_{0}}{T}\right) Z_{v}^{-1} R_{0}^{2},
$$

where the vibrational partition $Z_{v}$ is equal to 1.0150 at $296 \mathrm{~K}$ and $L$ is the Loschmidt's number equal to $2.68675 \times 10^{-19}$ molecule.cm ${ }^{-3} \cdot \mathrm{atm}^{-1}$.

(Figure 5)

(Figure 6) 
The results are plotted in Figs. 5-6 for each $K$ values versus $m$, where $m=-J, J, J+1$ for the $P_{-}, Q-, R$-branch transitions, respectively. First, it is quite interesting to observe the quality of the model used in Ref. [18]. Indeed, despite the fact that measurements in Ref. [18] were retrieved mainly for $R^{R}$ and $R^{Q}$ transitions (only $1 P^{R}$ and $5 R^{P}$ transitions, and no $P^{P}$ or $P^{Q}$ transition), the model predict well the sub-branches not measured in Ref. [18]. Our first calculation has been performed in the same way as in Ref. [18], fitting all transitions together. In order to refine the model for the strong $R^{Q}$ and $P^{Q}$ sub-branches, another analysis has been performed fitting separately the $R^{Q}$ and $P^{Q}$ sub-branches from the other sub-branches $\left(P^{P}, P^{R}\right.$, $R^{R}$ and $R^{P}$ ). This calculation is referred as this work ${ }^{*}$ in Table 3 and is plotted in dot line (in blue) on Figs. 5-6. The main differences between the two analyses can be observed in Fig. 6 for high $K$ values in the $R^{Q}$ and $P^{Q}$ sub-branches.

\section{(Table 3)}

In Table 3, the average ratio between our measurements and the calculation of Ref. [18] shows a systematic difference of around 3.5\%. Also the SD of the average ratio (obs/calc, see Table 3) show that the precision of our calculation is slightly better when using the calculation from this work* ${ }^{*}$, especially for $P^{Q}$ sub-branches when $K$ is increasing (see Figs. 5-6). Concerning comparisons between our measurements and those from literature, for 69 common lines with the Equivalent Width Method (EWW) [18] and 13 common lines with the Rautian Profile Fit Method (RPFM) [18], the average discrepancy between our measurements and those of Ref. [18] is equal to $(2.7 \pm 3.3) \%$ and $(3.2 \pm 2.1) \%$ respectively. A systematic deviation of around 3\% is observed with SD of around 3\%, consistent with the discrepancy found when compared our measurements with calculation of Ref. [18] and with the common $5 \%$ accuracy given for such measurements.

\subsection{Self-broadening coefficients}

Extensive measurements of broadening coefficients, obtained for various values of $K$ and for much larger $J$ values, allowed the study of the rotational dependence (in $J$ and $K$ ) of self-broadening coefficients. Such a work requires a large amount of measurements to retrieve the two parameters of Eq. (8) for each value of $J$. For $\mathrm{C}_{3 v}$ molecules, the study of Nemtchinov et al. [30] on $\mathrm{NH}_{3}$, on $\mathrm{CH}_{3} \mathrm{D}$ of Predoi-Cross et al. [31,32] or on $\mathrm{CH}_{3} \mathrm{Br}$ [2] and 
$\mathrm{CH}_{3} \mathrm{Cl}[9,10,12]$ can be cited as recent works dealing with the rotational dependence of broadening coefficients for large sets of $J$ and $K$ values. For methyl fluoride, such a study has, to our knowledge, never been done. Table 2 lists only $P^{Q}$ transitions for which $J$ values are from 0 to 37 and $K=3$. The whole set of measurements is available as supplementary material. No significant sub-branches dependence has been observed as for $\mathrm{CH}_{3} \mathrm{Cl}[9,10,12]$ and $\mathrm{CH}_{3} \mathrm{Br}$ [2]. As a consequence, the rotational dependence of the self-broadening is only characterized by the rotational quantum numbers $J$ and $K$ of the lower state. In order to model this rotational dependence, each set of measurements of same value of $J$ was fitted by the following equation:

$$
\gamma_{J}(K)=a_{J}^{0}+a_{J}^{2} K^{2}
$$

Examples of this model are given in Fig. 7 for $J=7,10,20,35$. The two coefficients $a_{J}^{0}$ and $a_{J}^{2}$ obtained for each set of same value of $J$ have then been plotted in Fig. 8 versus $J$ and the whole set of parameters (using Eq. (8)) are given in Table 4. As it can be observed, the zero and second order coefficients monotonically decrease in magnitude with increasing $J$. Note that the $a_{J}^{0}$ parameters correspond to the broadening coefficients for $K=0$. The $a_{J}^{2}$ parameters represent the $K$-rotational dependence which decreases $\left(a_{J}^{2}<0\right)$ the broadening coefficients as $K$ is increasing.

(Figure 7)

(Figure 8)

(Table 4)

The $J$ - and $K$-rotational dependences are also illustrated in Fig. 9 where the selfbroadening coefficients are plotted for the same value of $K$ versus $J$. In this Figure is also plotted the 13 measurements from Ref. [18] for $K=2,5,7$ and 9 using the Rautian profile fit method. These coefficients are close to our measurements and model, showing the consistency of this study.

(Figure 9)

Global comparison between the measured and calculated self-broadening coefficients lead to an average difference of $(0.2 \pm 8.1) \%$. 


\section{Line list generation}

The line list for the $v_{6}$ band of $\mathrm{CH}_{3} \mathrm{~F}$ has been built using calculated line positions (in $\mathrm{cm}^{-1}$ ) from Ref. [24], line intensities (for natural $\mathrm{CH}_{3} \mathrm{~F}$ in $\mathrm{cm} \cdot$ molecule ${ }^{-1}$ at $296 \mathrm{~K}$ ) based on This work* calculated with Eqs. (1-6) and parameters of Table 3, self-broadening coefficients calculated using Eq. (8) and parameters of Table 4 (substitutable smoothed or extrapolated values have been used when available). The energies of the lower state have been calculated using parameters of Ref. [25].

For $\mathrm{CH}_{3} \mathrm{X}$ molecules (X being an halogen atom) the $\mathrm{N}_{2}$-broadening coefficients are less $J$-and $K$-rotational dependent than the self-broadening coefficients [2,9], as shown in Fig. 10 , where are plotted empirical calculations of $\mathrm{N}_{2}$-broadening coefficients from literature for $\mathrm{CH}_{3} \mathrm{Cl}$ [9] and $\mathrm{CH}_{3} \mathrm{Br}$ [2]. On the contrary, the $\mathrm{N}_{2}$-broadening coefficients seem not to be so dependent of the $\mathrm{X}$ atom (see Fig. 11, where only $\mathrm{CH}_{3} \mathrm{Cl}$ and $\mathrm{CH}_{3} \mathrm{Br}$ are given).

(Figure 10)

(Figure 11)

Consequently in a first approximation we decided to add the $\mathrm{N}_{2}$-broadening coefficients of $\mathrm{CH}_{3} \mathrm{~F}$ to our line list based on the values obtained in Ref. [10] for $\mathrm{CH}_{3} \mathrm{Cl}$ (using the smoothed values from Table 2 of Ref. [10]). This effort for adding the $\mathrm{N}_{2}$-broadening coefficients is motivated by atmospheric applications.

The final line list contains line parameters for a total of 1499 transitions belonging to the $v_{6}$ band between 1067 and $1291 \mathrm{~cm}^{-1}$. A sample of this list is presented in Table 5 and the whole line list is available as supplementary material.

(Table 5) 


\section{Conclusion}

The present study on $\mathrm{CH}_{3} \mathrm{~F}$ has been devoted to the measurements of line positions, intensities and self-broadening coefficients at room temperature for 787 transitions of the $v_{6}$ band. The large set of measurements allowed performing $J$ - and $K$-rotational analysis of transition dipole moment squared and self-broadening coefficients in order to reproduce the experimental measurements and then to be able to generate a complete line list. The comparison with literature has shown good consistency since the average differences between our line positions and those calculated in Ref. [24] is equal to $-(0.02 \pm 0.24) 10^{-3} \mathrm{~cm}^{-1}$, the average discrepancy between our measured line intensities and those of Ref. [18] is equal to $(2.7 \pm 3.3) \%$ and $(3.2 \pm 2.1) \%$ depending on the method used in Ref. [18]. New Herman-Wallis factors have been used to improve the line intensities. A list of line positions, intensities, selfbroadening coefficients, and energy of the lower state has been build for 1499 transitions of the $v_{6}$ band. In order to complete the line list for atmospheric applications, the $\mathrm{N}_{2}$-broadening coefficients have been derived from the literature and added to the line list. This line list is available as supplementary material for atmospheric detection of $\mathrm{CH}_{3} \mathrm{~F}$ in the $8.5 \mu \mathrm{m}$ spectral region. 


\section{References}

[1] Kwabia Tchana F, Jacquemart D, Lacome N, Kleiner I, Orphal J. Absolute line intensities in methyl bromide: The 7- $\mu \mathrm{m}$ region. J Mole Spectrosc 2006;235:132-143.

[2] Jacquemart D, Kwabia Tchana F, Lacome N, Kleiner I. A complete set of line parameters for $\mathrm{CH}_{3} \mathrm{Br}$ in the 10- $\mu \mathrm{m}$ spectral region. J Quant Spectrosc Radiat Transf 2007;105:264-302.

[3] Tran H, Jacquemart D, Mandin JY, Lacome N. Line-mixing in the $v_{6} \mathrm{Q}$ branches of methyl bromide broadened by nitrogen: experiment and modelling. JQSRT 2008;109:119131.

[4] Jacquemart D, Tran $\mathrm{H}$. Temperature dependence of self- and $\mathrm{N}_{2}$-broadening coefficients for $\mathrm{CH}_{3} \mathrm{Br}$ in the 10- $\mu \mathrm{m}$ spectral region. J Quant Spectrosc Radiat Transf 2008;109:569-579.

[5] Gomez L, Tran H, Jacquemart D. Line-mixing in the $v_{6} Q$ branches of methyl bromide broadened by nitrogen: experiment and modelling at low temperatures. J Mol Spectrosc 2009;256:35-40.

[6] Gomez L, Jacquemart D, Bouanich JP, Boussetta Z, Aroui H. Theoretical calculations of self-broadening coefficients in the $v_{6}$ band of $\mathrm{CH}_{3} \mathrm{Br}$. J Quant Spectrosc Radiat Transf 2010;111:1252-1261.

[7] Boussetta Z, Aroui H, Jacquemart D, Gomez L, Bouanich JP. Theoretical calculations of $\mathrm{CH}_{3} \mathrm{Br} / \mathrm{N}_{2}$-broadening coefficients at various temperatures. J Quant Spectrosc Radiat Transf 2011;112:769-778.

[8] Bray C, Perrin A, Jaquemart D, Lacome N. The $v_{1}, v_{4}$ and $3 v_{6}$ bands of methyl chloride in the $3.4 \mu \mathrm{m}$ region: line positions and intensities. J Quant Spectrosc Radiat Transf 2011;112:2446-62.

[9] Bray C, Jacquemart D, Lacome N, Guinet M, Cuisset A, Eliet S, Hindle F, Mouret G, Rohart F, Buldyreva J. Self-broadening coefficients of methyl chloride transitions at room temperature. J Quant Spectrosc Radiat Transf 2013;116:88-100.

[10] Bray C, Jacquemart D, Buldyreva J, Lacome N, Perrin A. The $\mathrm{N}_{2}$-broadening coefficients of methyl chloride at room temperature. J Quant Spectrosc Radiat Transf 2012;113:1102-12.

[11] Bray C, Tran H, Jacquemart D, Lacome N. Line mixing in the ${ }^{Q} Q$ sub branches of the $v_{1}$ band of methyl chloride. J Quant Spectrosc Radiat Transf 2012;113:2182-8.

[12] Barbouchi Ramchani A, Jacquemart D, Dhib M, Aroui H. Line positions, intensities and self-broadening coefficients for the $v_{5}$ band of methyl chloride. J Quant Spectrosc Radiat Transf 2013;120:1-15.

[13] Barbouchi Ramchani A, Jacquemart D, Dhib M, Aroui H. Theoretical calculations of self-broadening coefficients for the $v_{5}$ band of methyl chloride at various temperatures. J Quant Spectrosc Radiat Transf 2014;134:1-8.

[14] Rothman LS, Gordon IE, Barbe A, Benner DC, Bernath PF, Birk M, et al. The HITRAN 2008 molecular spectroscopic database. J Quant Spectrosc Radiat Transf 2009;110:533-72. 
[15] Jacquinet-Husson N, Crepeau L, Armante R, Boutammine C, et al. The 2009 edition of the GEISA spectroscopic database. J Quant Spectrosc Radiat Transf 2011;112:2395-445.

[16] Papoušek D, Tesař R, Pracna P, Civiš S, Winnewisser M, Belov SP, Yu Tretyakov M. High resolution Fourier transform and submillimeter-wave study of the $v_{6}$ band of ${ }^{12} \mathrm{CH}_{3} \mathrm{~F}$. J Mol Spectrosc 1991;147:279-299.

[17] Papoušek D, Pracna P, Winnewisser M, Klee S, Demaison J. Simultaneous rovibrational analysis of the $v_{2}, v_{3}, v_{5}$, and $v_{6}$ bands of $\mathrm{H}_{3}{ }^{12} \mathrm{CF}$. J Mol Spectrosc 1999;196:319-23.

[18] Lepère M, Blanquet $\mathrm{G}$, Walrand $\mathrm{J}$, Bouanich JP. Line intensities in the $v_{6}$ band of $\mathrm{CH}_{3} \mathrm{~F}$ at $8.5 \mu \mathrm{m}$. J Mol Spectrosc 1996;180:218-226.

[19] Lerot C, Blanquet G, Bouanich JP, Walrand J, Lepère M. Self-broadening coefficients in the $v_{2}$ and $v_{5}$ bands of ${ }^{12} \mathrm{CH}_{3} \mathrm{~F}$ at 183 and 298K. J Mol Spectrosc 2005;230:153-60.

[20] Lerot C, Blanquet $\mathrm{G}$, Bouanich JP, Walrand J, Lepère $\mathrm{M}$. $\mathrm{N}_{2}$-and $\mathrm{O}_{2}$-broadening coefficients in the $v_{2}$ and $v_{5}$ bands of ${ }^{12} \mathrm{CH}_{3} \mathrm{~F}$ at 183 and 298K. J Mol Spectrosc 2006;235:196-205.

[21] Lepère M, Gobeille R, Kolodziejski N, Malathy Devi V, Chris Benner D, Smith MAH, McMichael W, Aoaeh B, Wilkinson K, Mantz AW. Analysis of tunable diode-laser spectra of ${ }^{R} Q(J, 0)$ lines in $\mathrm{CH}_{3} \mathrm{~F}$ near $1475 \mathrm{~cm}^{-1}$ using a multispectrum fitting technique. $\mathrm{J} \mathrm{Mol}$ Spectrosc 2004;224:7-12.

[22] Lance B, Lepère M, Blanquet G, Walrand J, Bouanich JP. Self-broadening and linestrength in the $v_{2}$ and $v_{5}$ bands of $\mathrm{CH}_{3} \mathrm{~F}$. J Mol Spectrosc 1996;180:100-9.

[23] Guerin D, Nischan M, Clark D, Dunjko V, Mantz W. Low-pressure Measurements of self and air broadening coefficients in the $v_{2}$ and $v_{5}$ bands of ${ }^{12} \mathrm{CH}_{3} \mathrm{~F}$. J Mol Spectrosc 1994;166:130-6.

[24] Private communication from P. Pracna (2012) based on the work: Papoušek D, Pracna P, Winnewisser M, Klee S, Demaison J. Simultaneous rovibrational analysis of the $v_{2}, v_{3}, v_{5}$, and $v_{6}$ bands of $\mathrm{H}_{3}{ }^{12} \mathrm{CF}$. J Mol Spectrosc 1999;196:319-23.

[25] Papoušek D, Hsu YC, Chen HS, Pracna P, Klee S, Winnewisser M, Demainson J. Far infrared spectrum and ground state parameters of ${ }^{12} \mathrm{CH}_{3} \mathrm{~F}$. J Mol Spectrosc 1993;159:33-41.

[26] Jacquemart D, Mandin JY, Dana V, Picqué N, Guelachvili G. A multispectrum fitting procedure to deduce molecular line parameters. Application to the 3-0 band of ${ }^{12} \mathrm{C}^{16} \mathrm{O}$. Eur Phys J D 2001;14:55-69.

[27] Rothman LS, Gordon IE, Babikov Y, Barbe A et al. The HITRAN2012 molecular spectroscopic database. J Quant Spectrosc Radiat Transf 130,4-50(2013).

[28] Miller CE and Brown LR. Near infrared spectroscopy of carbon dioxide $\mathrm{I} .{ }^{16} \mathrm{O}^{12} \mathrm{C}^{16} \mathrm{O}$ line positions. J Quant Spectrosc Radiat Transf 2004;228:329-54. 
[29] Tashkun SA, Perevalov VI, Teffo JL, Bykov AD, Lavrentieva NN. CDSD-1000, the high-temperature carbon dioxide spectroscopic databank. J Quant Spectrosc Radiat Transf 2003;82:165-96.

[30] Nemtchinov V, Sung, K, Varanasi P. Measurements of line intensities and half-widths in the 10- $\mu \mathrm{m}$ bands of ${ }^{14} \mathrm{NH}_{3}$. J Quant Spectrosc Radiat Transf 2004;83:243-65.

[31] Predoi-Cross A, Hambrook K, Brawley-Tremblay S, Bouanich JP, Malathy Devi V, Smith MAH. Room-temperature broadening and pressure-shift coefficients in the $v_{2}$ band of $\mathrm{CH}_{3} \mathrm{D}-\mathrm{O}_{2}$ : Measurements and semi-classical calculations. J Mol Spectrosc 2006;236;75-90.

[32] Predoi-Cross A, Hambrook K, Brawley-Tremblay S, Bouanich JP, Smith MAH. Measurements and theoretical calculations of $\mathrm{N}_{2}$-broadening and $\mathrm{N}_{2}$-shifting coefficients in the $v_{2}$ band of $\mathrm{CH}_{3} \mathrm{D}$. J Mol Spectrosc 2006;235;35-53. 
Figure 1 : Overview of spectrum 5 (see Table 1) between 950 and $1250 \mathrm{~cm}^{-1}$.

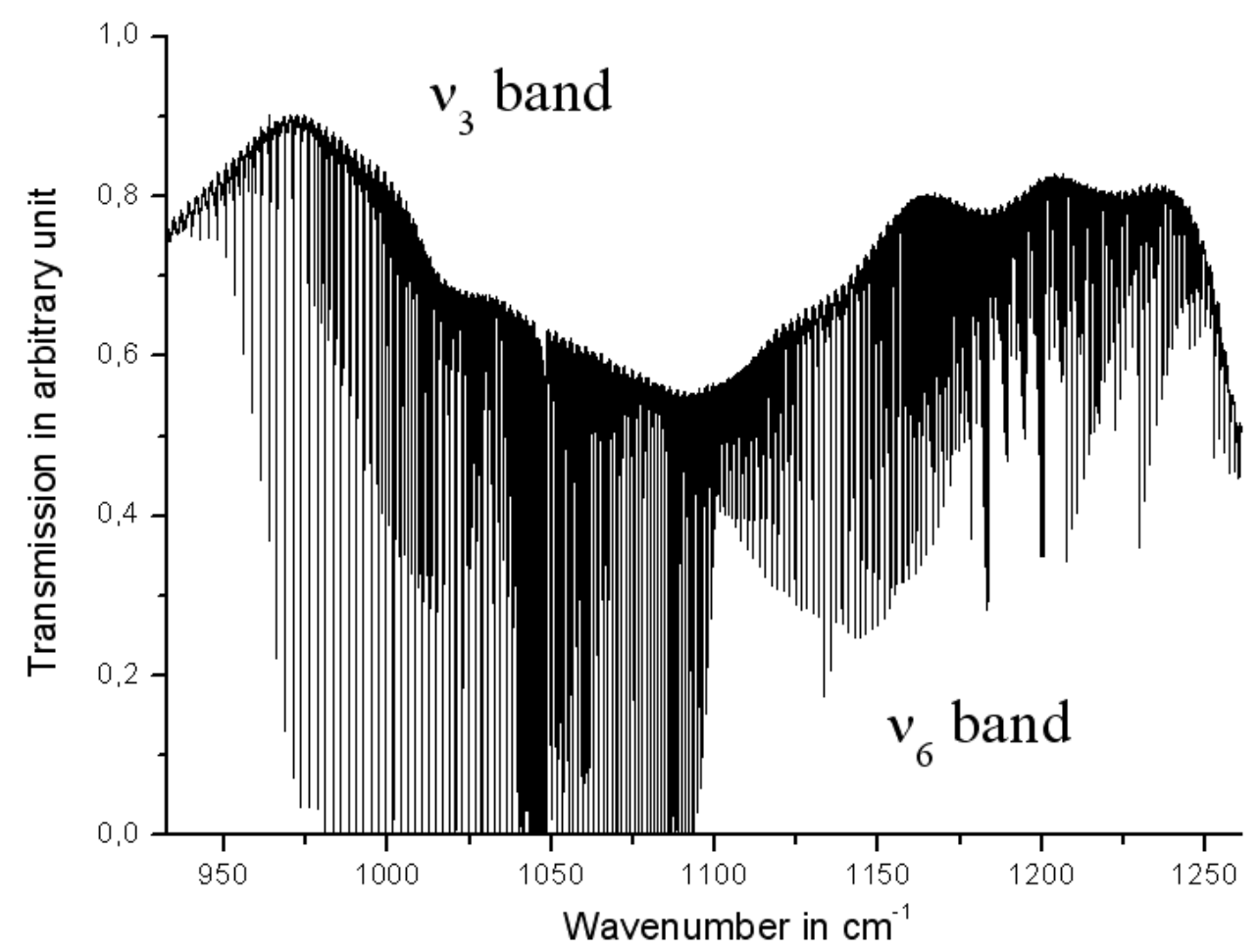

Figure $2: R^{Q}$ sub-branches structure between 1180 and $1240 \mathrm{~cm}^{-1}$. Only $R_{0}^{Q}, R_{3}^{Q}, R_{6}^{Q}$ sub-branches are indicated.

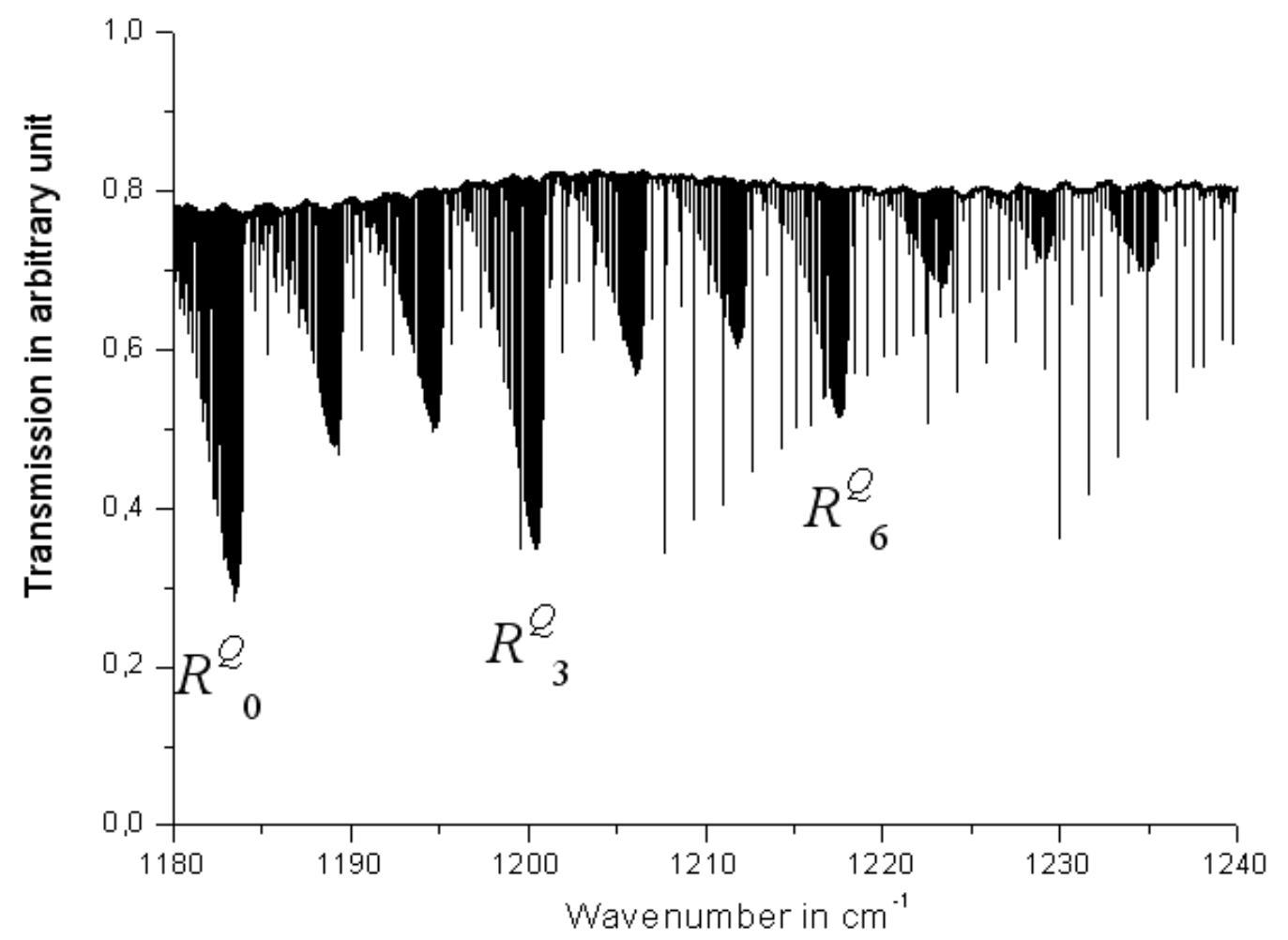


Figure 3 : Sample fit of 3 transitions simultaneously on spectra 1-7 (see Table 1). The fitting spectral range is equal to $0.080 \mathrm{~cm}^{-1}$. The 3 fitted transitions are the $P_{5}^{P}(15), P_{6}{ }_{6}(12)$ and $P^{P}{ }_{7}(9)$ between 1130.024 and $1130.104 \mathrm{~cm}^{-1}$.

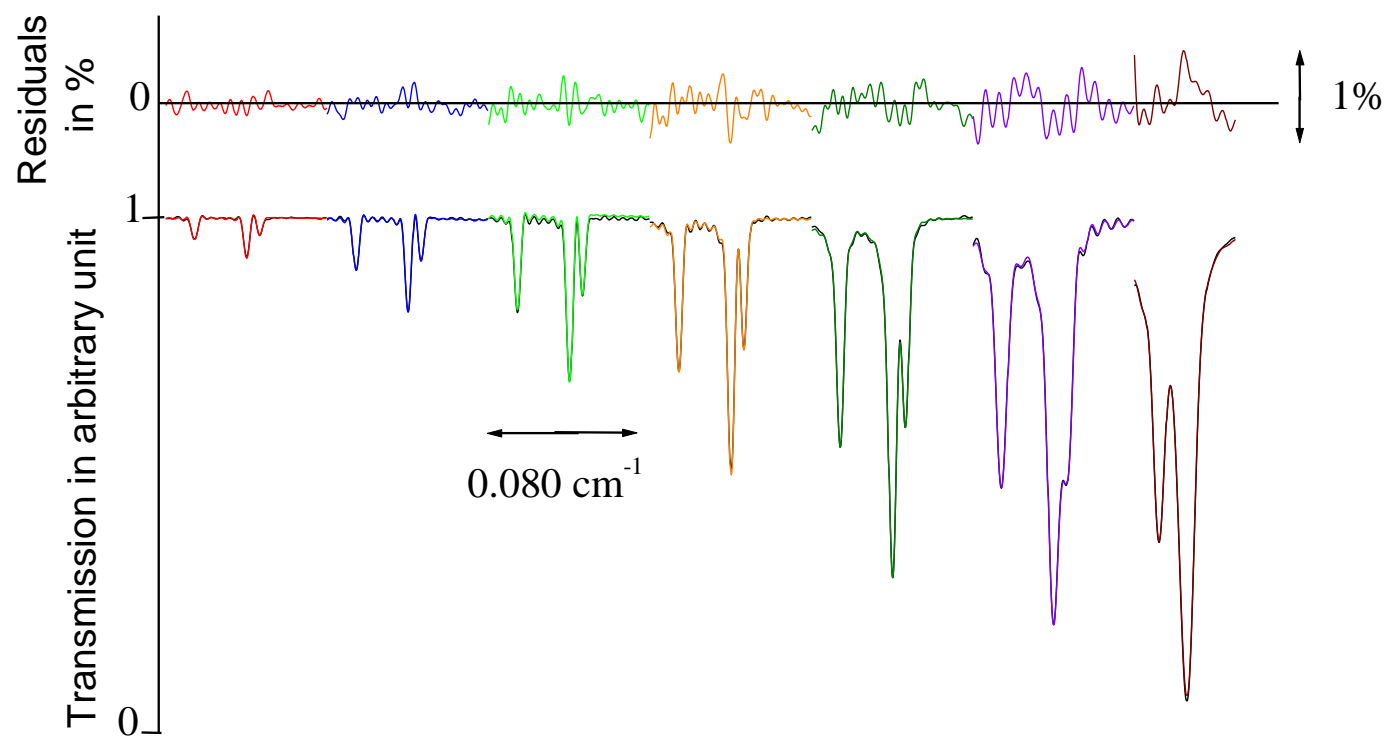

Figure 4 : Difference between line positions measured in this work and the calculated positions from Ref. [24] plotted versus line intensities at $296 \mathrm{~K}$.

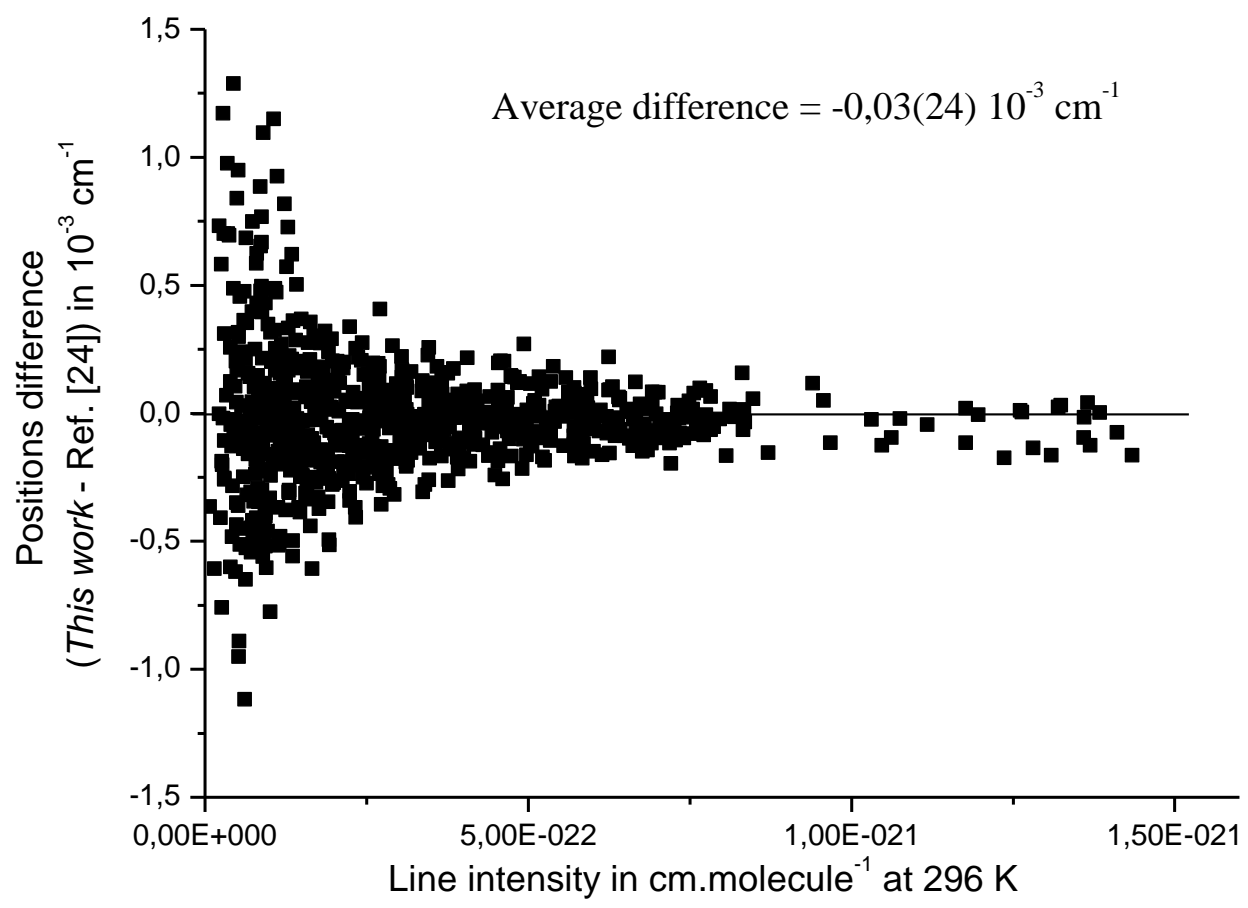


Figure 5: Transition dipole moment squared obtained for $K=0$ to 5 from measurements and calculation using Herman-Wallis coefficients. The straight line represents the calculation from Ref. [18], whereas the red dash and blue dot lines correspond to calculation performed in this work (see text). The experimental measurements are plotted using open and solid squares for $\left(R^{P}, R^{R}\right)$ and $\left(P^{P}\right.$, $\left.P^{R}\right)$ sub-branches respectively, open and solid triangles for $R^{Q}$ and $P^{Q}$ sub-branches respectively. The red open circles and stars stand for the measurements of Lepère et al. [18] for $\left(R^{P}, R^{R}\right)$ and $R^{Q}$ subbranches respectively.
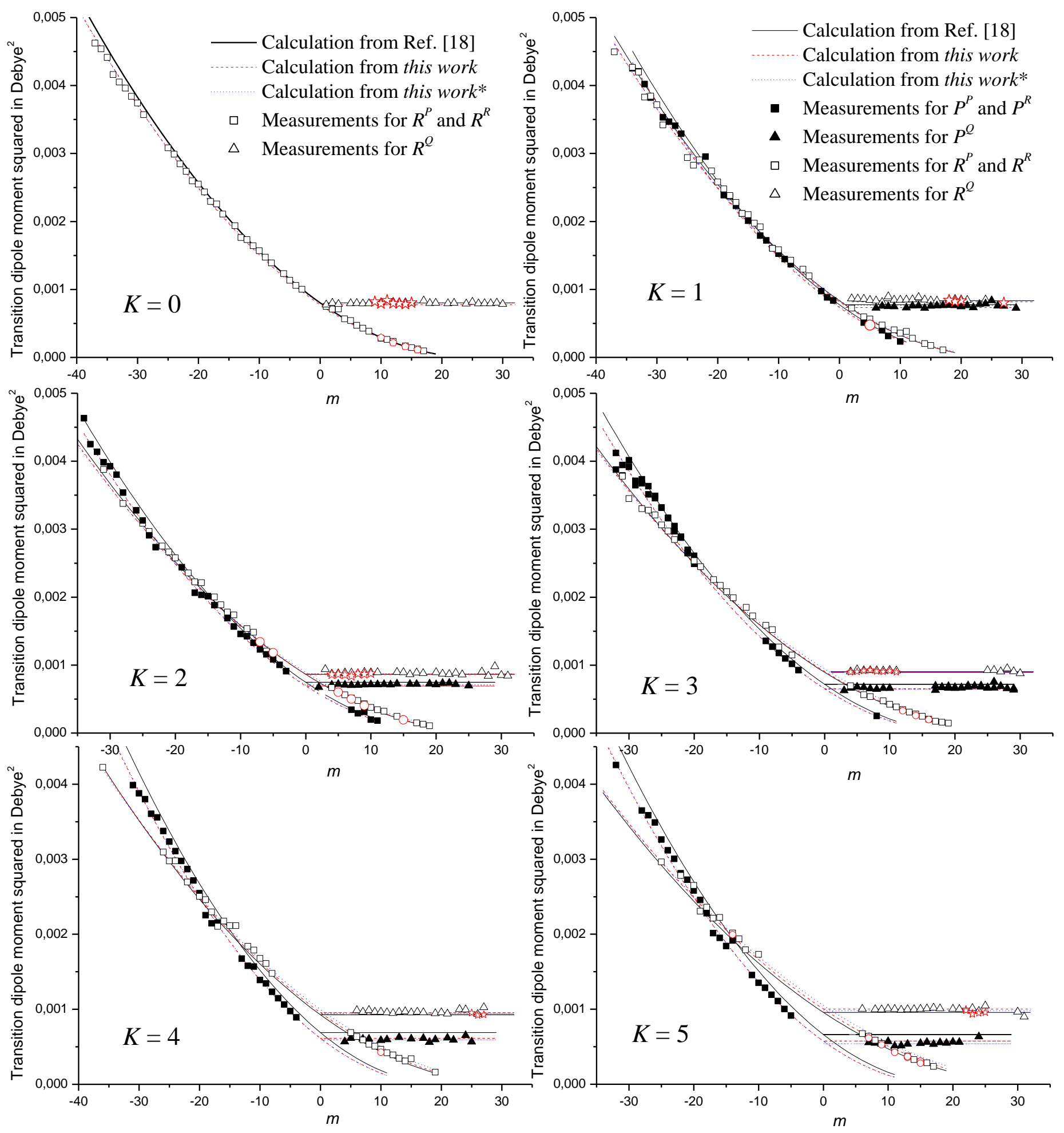
Figure 6: Transition dipole moment squared obtained for $K=6$ to 9 from measurements and calculation using Herman-Wallis coefficients. The straight line represents the calculation from Ref. [18], whereas the red dash and blue dot lines correspond to calculation performed in this work (see text). The experimental measurements are plotted using open and solid squares for $\left(R^{P}, R^{R}\right)$ and $\left(P^{P}\right.$, $\left.P^{R}\right)$ sub-branches respectively, open and solid triangles for $R^{Q}$ and $P^{Q}$ sub-branches respectively. The red open circles and stars stand for the measurements of Lepère et al. [18] for $\left(R^{P}, R^{R}\right)$ and $R^{Q}$ subbranches respectively.
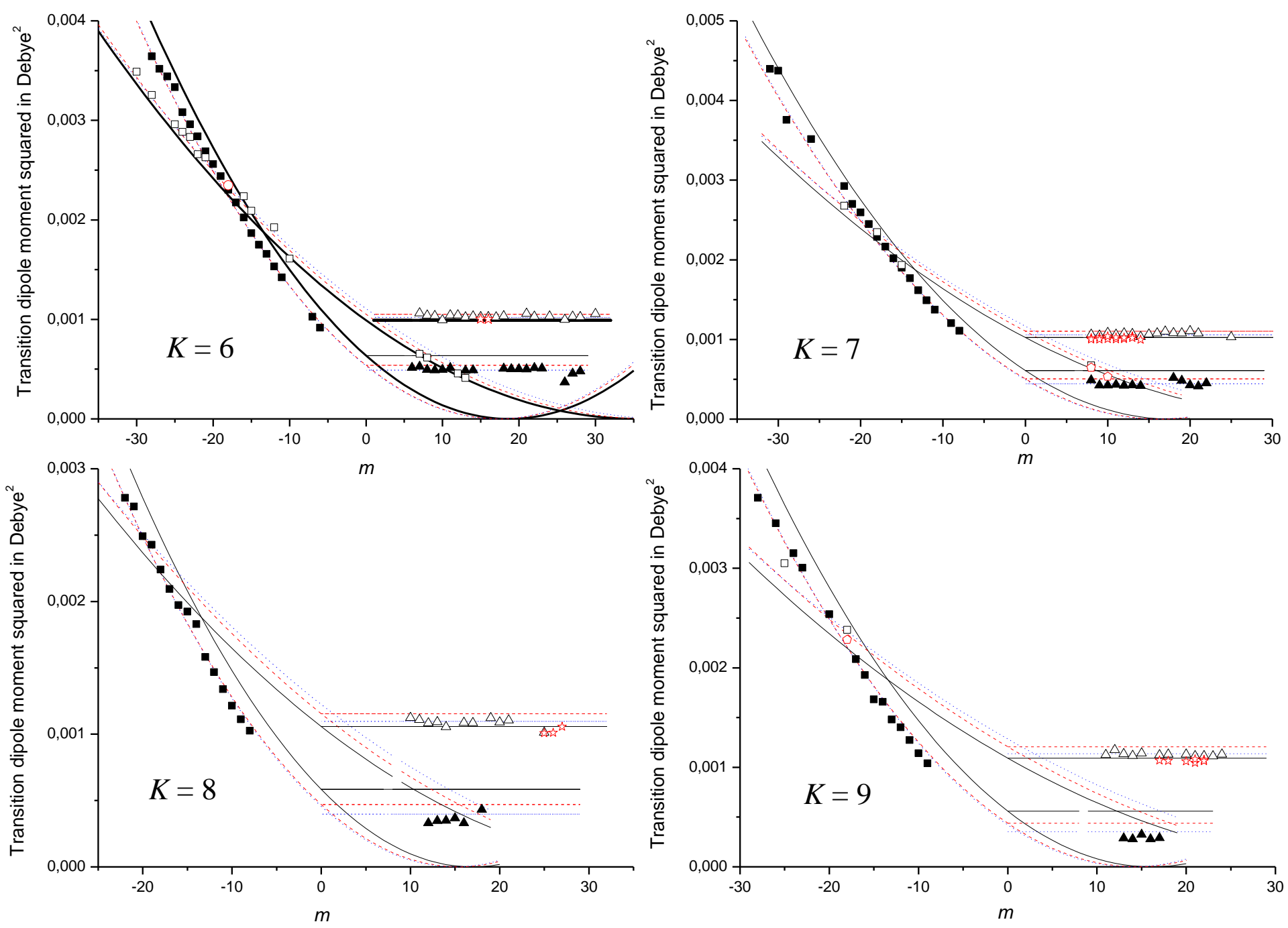
Figure 7 : Example of the polynomial fit in $K^{2}$ (see Eq. (8)) of the self-broadening coefficients for sets of measurements corresponding to $J=5, J=8, J=10$, and $J=20$. The square symbols represent the measured self-broadening coefficients, whereas the continuous lines stand for their fits using Eq. (8).
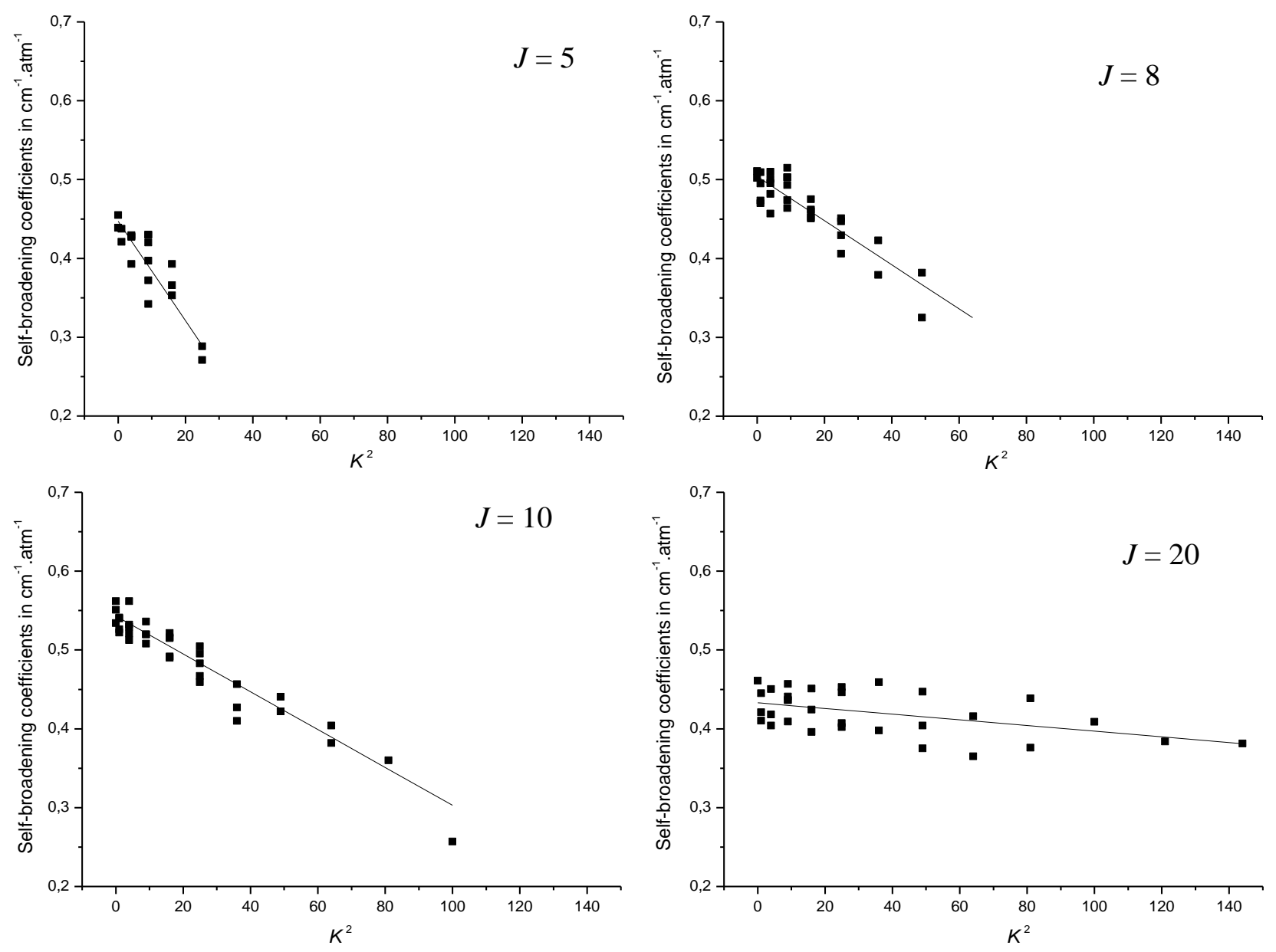
Figure 8: Parameters $a_{J}^{0}$ and $a_{J}^{2}$ (solid squares) obtained for each set of same $J$ value from the fit (using Eq. (8)) of the measured self-broadening coefficients. The open squares correspond to smoothed and extrapolated values for high $J$ values.
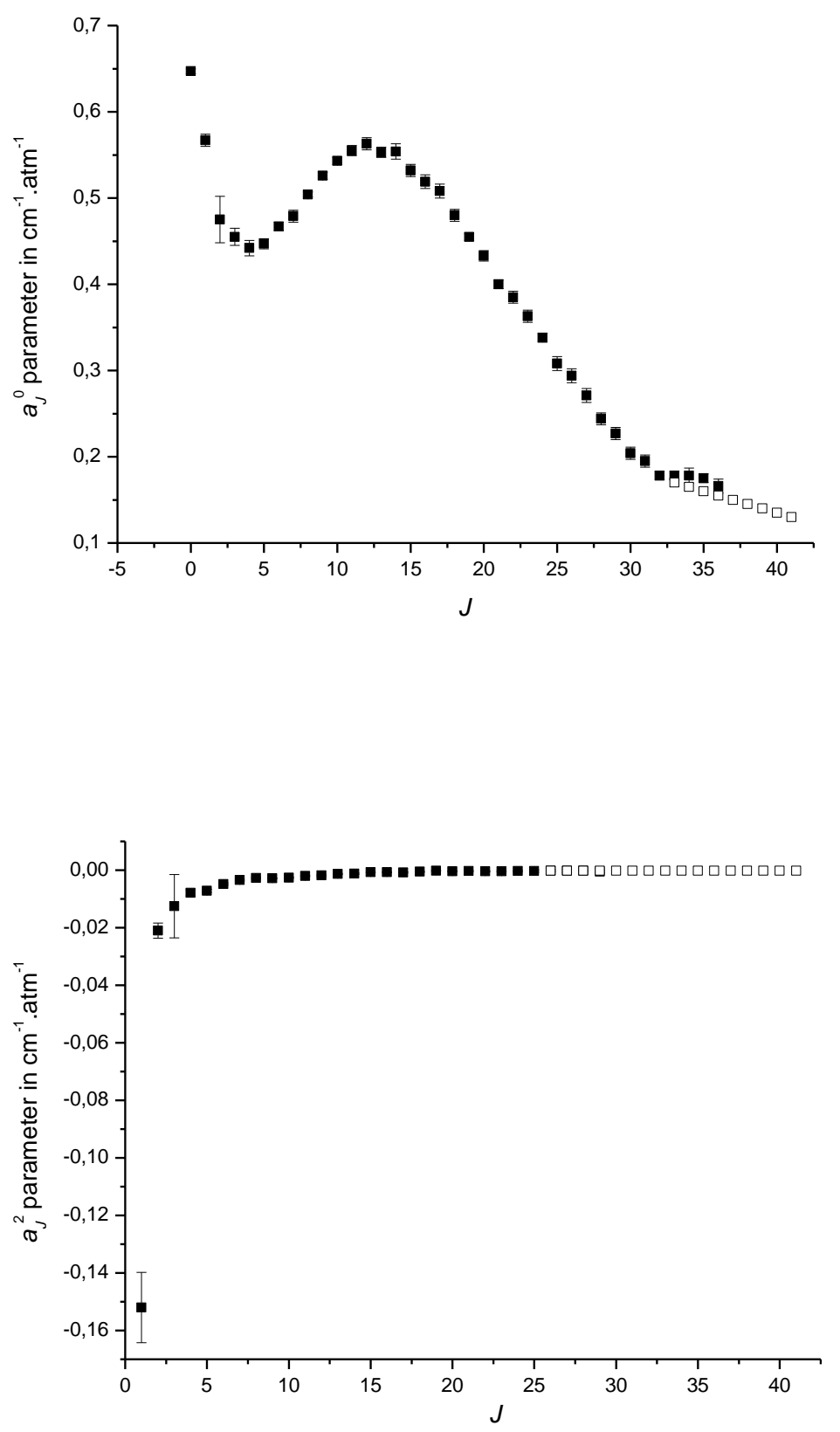
Figure 9. $J$ and $K$ dependence observed and calculated for all the self-broadening coefficients measured in this work. The open triangles symbols represent the measured widths, and the solid squares symbols have been used to represent the self-broadening coefficients calculated using Eq. (7) and parameters of Table 4. The open stars stand for measurements from Ref. [18] for $K=2,5,7$ and 9 using Rautian Profile Fit Method.
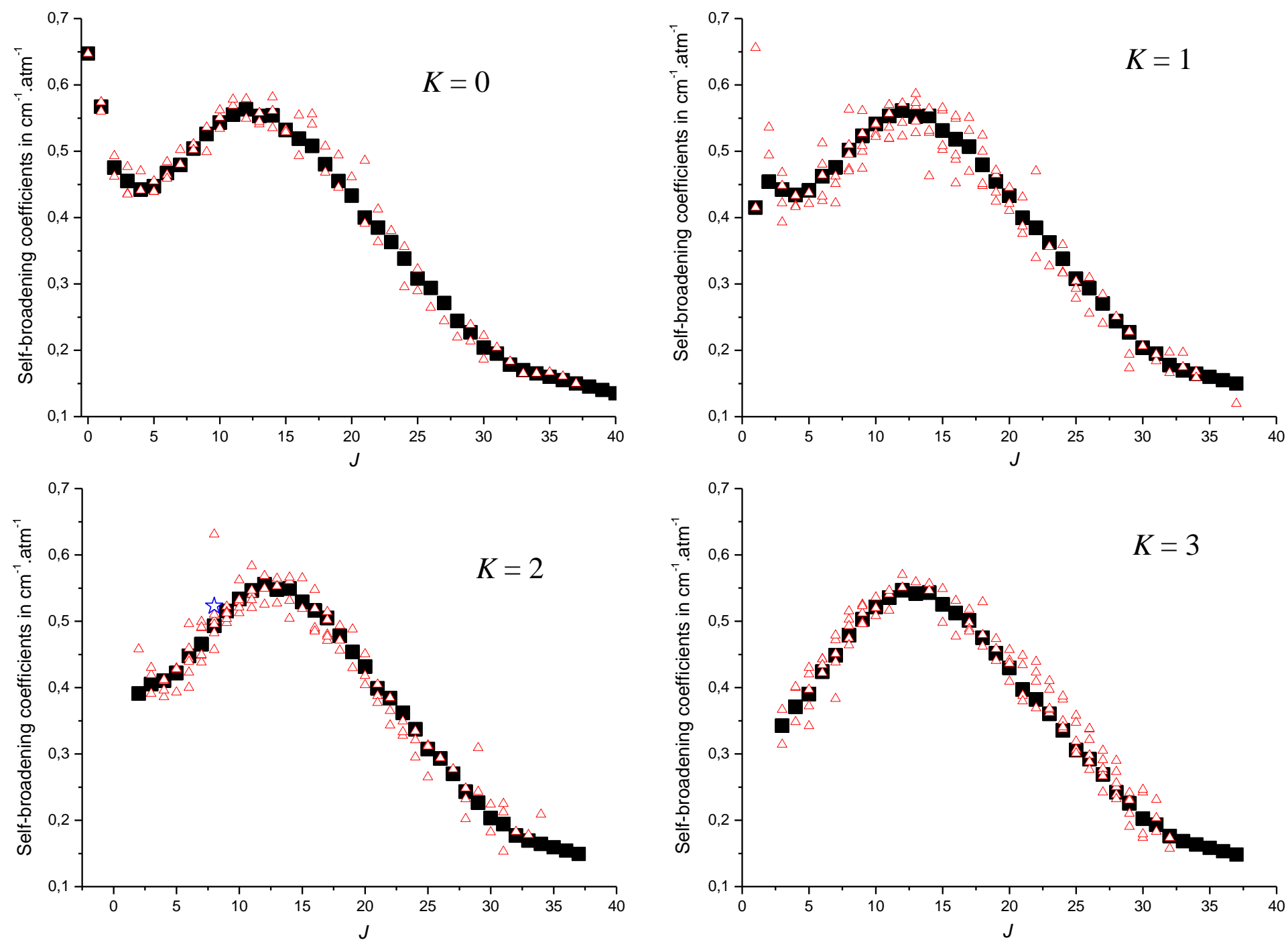
Figure 9 (suite)
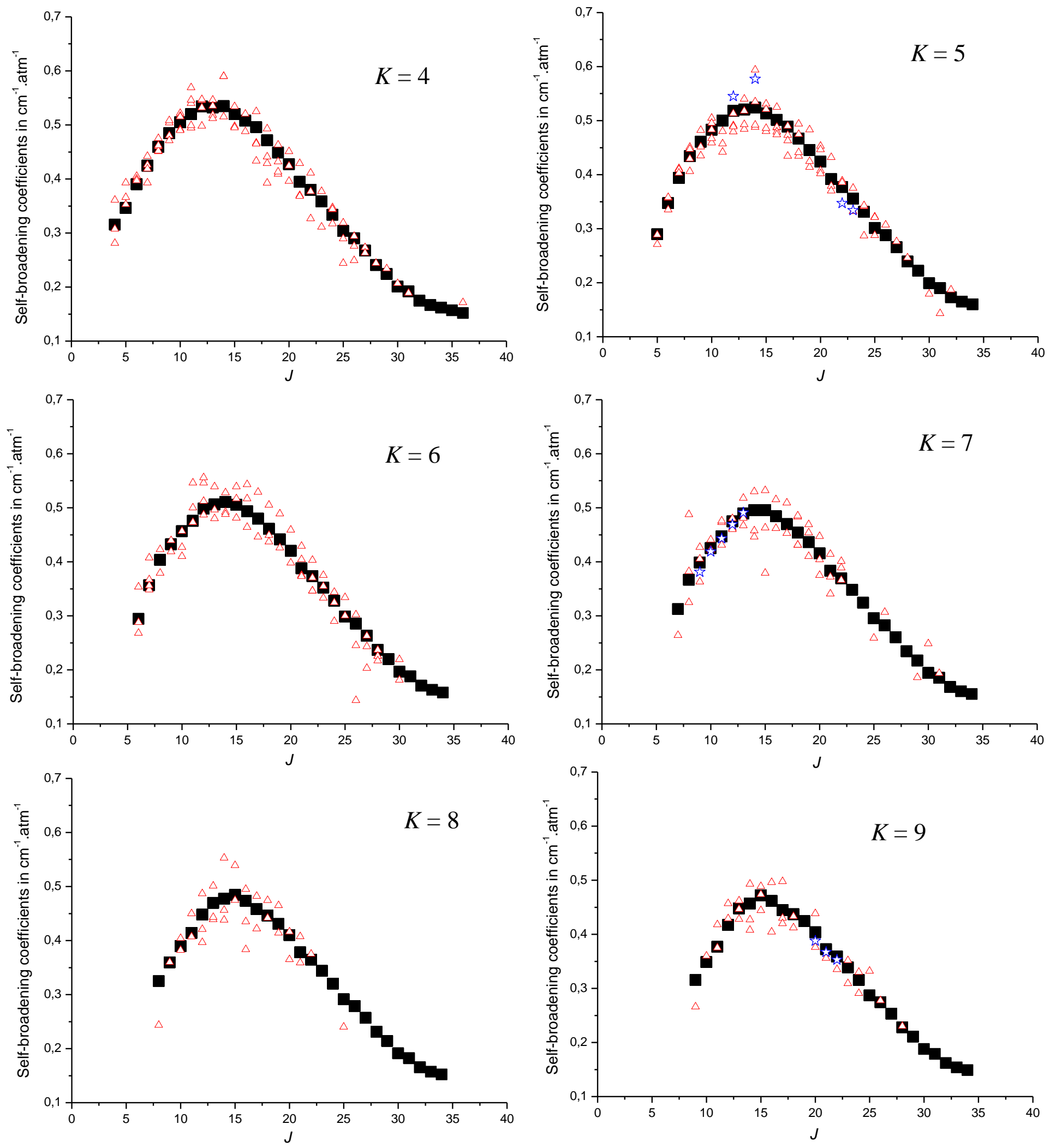
Figure 10: Comparisons of $a_{J}^{0}$ and $a_{J}^{2}$ parameters (in $\mathrm{cm}^{-1} \cdot \mathrm{atm}^{-1}$ ) obtained for selfbroadening coefficients in this work for $\mathrm{CH}_{3} \mathrm{~F}$ (solid circles), in Ref. [2] for $\mathrm{CH}_{3} \mathrm{Br}$ (solid squares) and in Ref. [9] for $\mathrm{CH}_{3} \mathrm{Cl}$ (solid triangles). The error bars correspond to 1SD (Standard Deviation) of the fit of the concerning parameters.
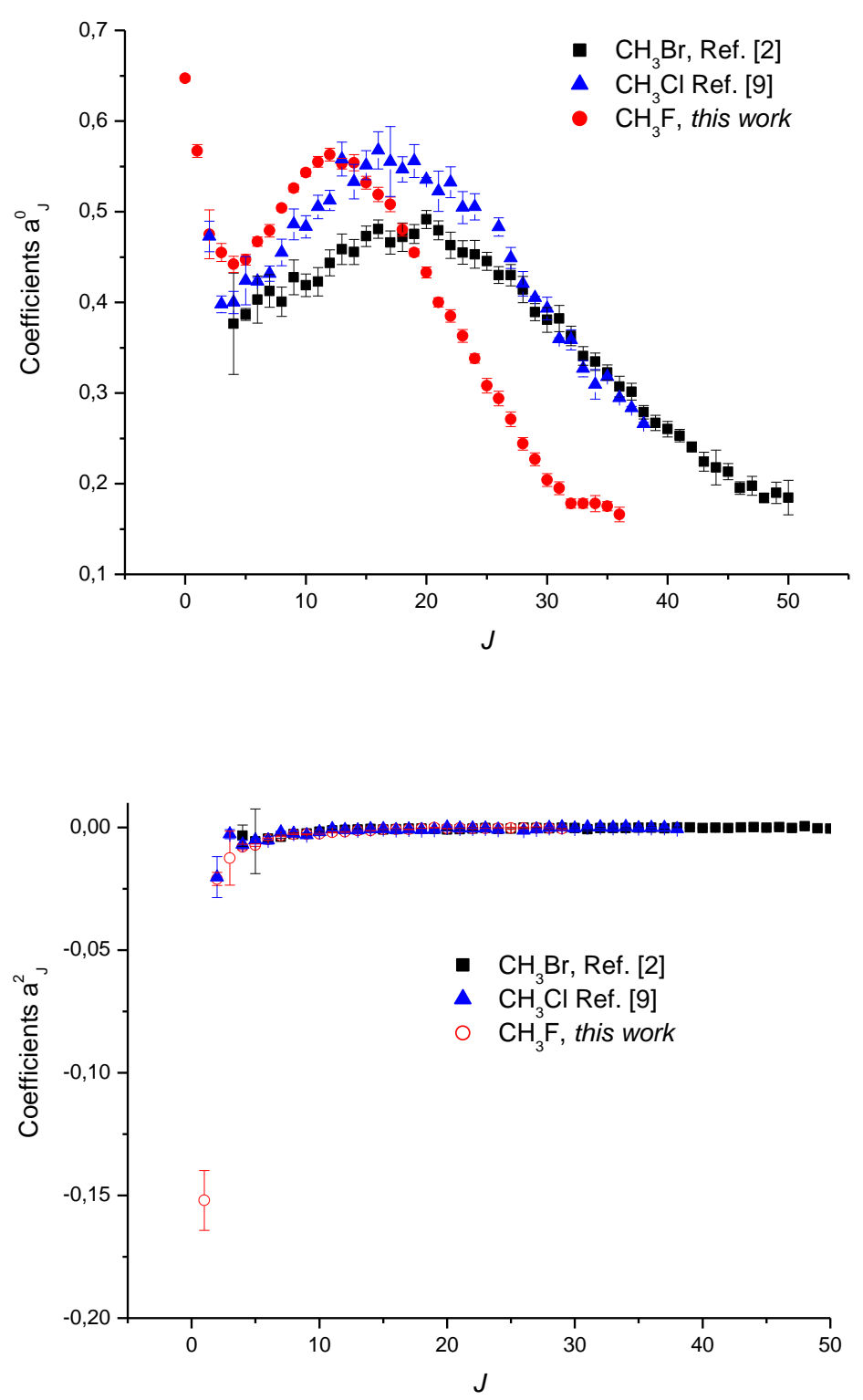
Figure 11 : Comparisons of $a_{J}^{0}$ and $a_{J}^{2}$ parameters $\left(\mathrm{in}^{-1} \cdot \mathrm{atm}^{-1}\right.$ ) obtained for $\mathrm{N}_{2}$-broadening coefficients in Ref. [2] for $\mathrm{CH}_{3} \mathrm{Br}$ (solid squares) and in Ref. [9] for $\mathrm{CH}_{3} \mathrm{Cl}$ (solid triangles). The error bars correspond to $1 \mathrm{SD}$ of the fit of the concerning parameters.
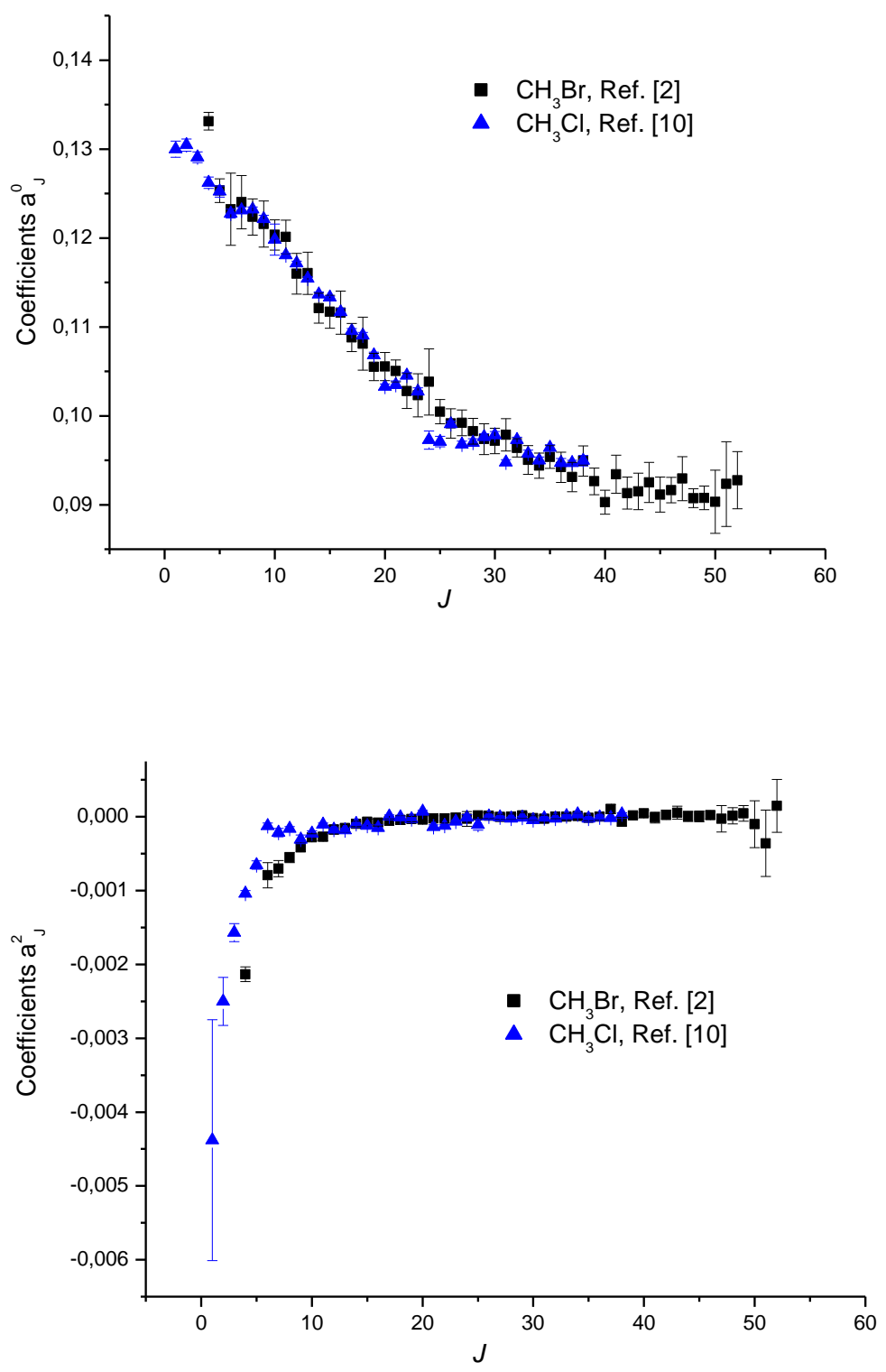
Table 1 : Experimental conditions of the FT spectra recorded in this work.

\begin{tabular}{ccccc}
\hline$\#$ & $\begin{array}{c}\text { Pressure of } \\
\mathrm{CH}_{3} \mathrm{~F} \text { (in mbar) }\end{array}$ & $\begin{array}{c}\text { Absorption } \\
\text { path (in cm) }\end{array}$ & $\begin{array}{c}\text { Bruker resolution } \\
\text { (in } \mathrm{cm}^{-1} \text { ) }\end{array}$ & $\begin{array}{c}\text { Temperature } \\
\left.\text { (in }{ }^{\circ} \mathrm{K}\right)\end{array}$ \\
\hline 1 & 0.1037 & 68.8 & 0.004 & $295.1_{5}$ \\
2 & 0.2620 & 68.8 & 0.004 & $294.0_{5}$ \\
3 & 0.5379 & 68.8 & 0.004 & $294.1_{5}$ \\
4 & 1.0500 & 68.8 & 0.004 & $294.2_{5}$ \\
5 & 2.236 & 68.8 & 0.004 & $294.6_{5}$ \\
6 & 3.950 & 68.8 & 0.006 & $294.5_{5}$ \\
7 & 9.672 & 68.8 & 0.012 & $295.2_{5}$ \\
8 & 0.0868 & 68.8 & 0.005 & $295.2_{5}$ \\
\hline
\end{tabular}

Note: The purity of the sample of $\mathrm{CH}_{3} \mathrm{~F}$ is $99 \%$. Bruker resolution corresponds to $0.9 / \Delta \max$, where $\Delta \max$ is the maximum optical depth difference. The aperture radius from the iris is equal to 0.65 $\mathrm{mm}$ and the focal length is equal to $418 \mathrm{~mm}$. Spectrum 8 was recorded without the optical filter used for spectra 1-7 in order to perform wavenumber calibration with $\mathrm{H}_{2} \mathrm{O}$ and $\mathrm{CO}_{2}$ traces inside the tank of the interferometer. 
Table 2: Sample of measurements and calculations performed in this work concerning line positions (in $\mathrm{cm}^{-1}$ ), line intensities (in natural abundance, in $\mathrm{cm}$.molecule ${ }^{-1}$ at $296 \mathrm{~K}$ ) and self-broadening coefficients in $\mathrm{cm}^{-1} \cdot \mathrm{atm}^{-1}$ at $296 \mathrm{~K}$. The two ratios correspond to our measured line intensity divided by the calculated intensity (for the first ratio the calculation comes from This work, and for the second one from This work ${ }^{*}$ ). The Dif heading column (in $10^{-3} \mathrm{~cm}^{-1}$ ) is the difference between our measured line positions and the one calculated in Ref. [24]. The whole set of measurements and comparisons is available as supplementary material. Note that this list has been sorted by $K$ values, then sub-branches and $m$ values.

\begin{tabular}{|c|c|c|c|c|c|c|c|c|c|c|c|c|c|}
\hline \multicolumn{4}{|c|}{ Assignment } & \multicolumn{2}{|c|}{ Line positions } & \multirow{2}{*}{$\begin{array}{c}\text { Dif } \\
\text { obs-calc }\end{array}$} & \multicolumn{3}{|c|}{ Line intensities } & \multicolumn{2}{|c|}{ Ratios } & \multicolumn{2}{|c|}{ Self-broadening } \\
\hline $\mathrm{Br}$ & J & $K$ & $m$ & obs & $\mathrm{CaIC}$ & & obs & This work & This work* & & & Calc & obs \\
\hline$P^{Q}$ & 3 & 3 & 3 & 1167.22945 & 1167.22976 & -0.31 & $0.1141 \mathrm{E}-21$ & $0.1186 \mathrm{E}-21$ & $0.1183 E-21$ & 0.962 & 0.965 & 0.343 & 0.367 \\
\hline$P^{Q}$ & 3 & 3 & 3 & 1167.22945 & 1167.22975 & -0.30 & $0.1141 \mathrm{E}-21$ & $0.1186 \mathrm{E}-21$ & $0.1183 \mathrm{E}-21$ & 0.962 & 0.965 & 0.343 & 0.367 \\
\hline$P^{Q}$ & 4 & 3 & 4 & 1167.19835 & 1167.19845 & -0.10 & $0.2104 \mathrm{E}-21$ & $0.2066 E-21$ & $0.2060 \mathrm{E}-21$ & 1.018 & 1.021 & 0.371 & 0.401 \\
\hline$P^{Q}$ & 4 & 3 & 4 & 1167.19835 & 1167.19844 & -0.09 & $0.2104 \mathrm{E}-21$ & $0.2066 E-21$ & $0.2060 \mathrm{E}-21$ & 1.018 & 1.021 & 0.371 & 0.401 \\
\hline$P^{Q}$ & 5 & 3 & 5 & 1167.15945 & 1167.15928 & 0.17 & $0.2885 \mathrm{E}-21$ & $0.2768 E-21$ & $0.2760 \mathrm{E}-21$ & 1.042 & 1.045 & 0.390 & 0.430 \\
\hline$P^{Q}$ & 6 & 3 & 6 & 1167.11225 & 1167.11229 & -0.04 & $0.3452 \mathrm{E}-21$ & $0.3335 E-21$ & $0.3325 E-21$ & 1.035 & 1.038 & 0.424 & 0.443 \\
\hline$P^{Q}$ & 6 & 3 & 6 & 1167.11225 & 1167.11233 & -0.08 & $0.3452 E-21$ & $0.3335 E-21$ & $0.3325 E-21$ & 1.035 & 1.038 & 0.424 & 0.443 \\
\hline$P^{Q}$ & 7 & 3 & 7 & 1167.05745 & 1167.05753 & -0.08 & $0.3793 E-21$ & $0.3783 E-21$ & $0.3772 \mathrm{E}-21$ & 1.003 & 1.006 & 0.448 & 0.451 \\
\hline$P^{Q}$ & 7 & 3 & 7 & 1167.05745 & 1167.05745 & 0.00 & $0.3793 \mathrm{E}-21$ & $0.3783 E-21$ & $0.3772 \mathrm{E}-21$ & 1.003 & 1.006 & 0.448 & 0.451 \\
\hline$P^{Q}$ & 8 & 3 & 8 & 1166.99485 & 1166.99489 & -0.04 & $0.4088 \mathrm{E}-21$ & $0.4120 E-21$ & $0.4107 \mathrm{E}-21$ & 0.992 & 0.995 & 0.479 & 0.474 \\
\hline$P^{Q}$ & 8 & 3 & 8 & 1166.99485 & 1166.99476 & 0.09 & $0.4088 \mathrm{E}-21$ & $0.4120 E-21$ & $0.4107 \mathrm{E}-21$ & 0.992 & 0.995 & 0.479 & 0.474 \\
\hline$P^{Q}$ & 9 & 3 & 9 & 1166.92435 & 1166.92441 & -0.06 & $0.4410 \mathrm{E}-21$ & $0.4351 E-21$ & $0.4338 \mathrm{E}-21$ & 1.014 & 1.017 & 0.503 & 0.498 \\
\hline$P^{Q}$ & 9 & 3 & 9 & 1166.92435 & 1166.92421 & 0.14 & $0.4410 E-21$ & $0.4351 E-21$ & $0.4338 \mathrm{E}-21$ & 1.014 & 1.017 & 0.503 & 0.498 \\
\hline$P^{Q}$ & 10 & 3 & 10 & 1166.84605 & 1166.84578 & 0.27 & $0.4545 E-21$ & $0.4484 \mathrm{E}-21$ & $0.4471 \mathrm{E}-21$ & 1.014 & 1.017 & 0.521 & 0.520 \\
\hline$P^{Q}$ & 17 & 3 & 17 & 1166.07555 & 1166.07567 & -0.12 & $0.3344 \mathrm{E}-21$ & $0.3443 E-21$ & $0.3433 E-21$ & 0.971 & 0.974 & 0.501 & 0.488 \\
\hline$P^{Q}$ & 17 & 3 & 17 & 1166.07815 & 1166.07811 & 0.04 & $0.3665 \mathrm{E}-21$ & $0.3443 E-21$ & $0.3433 E-21$ & 1.064 & 1.068 & 0.501 & 0.498 \\
\hline$P^{Q}$ & 18 & 3 & 18 & 1165.93695 & 1165.93696 & -0.01 & $0.3242 E-21$ & $0.3143 E-21$ & $0.3134 \mathrm{E}-21$ & 1.031 & 1.035 & 0.475 & 0.480 \\
\hline$P^{Q}$ & 18 & 3 & 18 & 1165.93365 & 1165.93391 & -0.26 & $0.3267 \mathrm{E}-21$ & $0.3143 E-21$ & $0.3134 \mathrm{E}-21$ & 1.039 & 1.043 & 0.475 & 0.462 \\
\hline$P^{Q}$ & 19 & 3 & 19 & 1165.78805 & 1165.78795 & 0.10 & $0.2883 E-21$ & $0.2836 \mathrm{E}-21$ & $0.2828 \mathrm{E}-21$ & 1.017 & 1.020 & 0.452 & 0.441 \\
\hline$P^{Q}$ & 19 & 3 & 19 & 1165.78415 & 1165.78418 & -0.03 & $0.2998 \mathrm{E}-21$ & $0.2836 \mathrm{E}-21$ & $0.2828 \mathrm{E}-21$ & 1.057 & 1.060 & 0.452 & 0.458 \\
\hline$P^{Q}$ & 20 & 3 & 20 & 1165.62625 & 1165.62645 & -0.20 & $0.2568 \mathrm{E}-21$ & $0.2531 E-21$ & $0.2523 E-21$ & 1.015 & 1.018 & 0.430 & 0.409 \\
\hline$P^{Q}$ & 20 & 3 & 20 & 1165.63115 & 1165.63106 & 0.09 & $0.2623 E-21$ & $0.2531 E-21$ & $0.2523 E-21$ & 1.036 & 1.039 & 0.430 & 0.436 \\
\hline$P^{Q}$ & 21 & 3 & 21 & 1165.46645 & 1165.46630 & 0.15 & $0.2283 \mathrm{E}-21$ & $0.2234 \mathrm{E}-21$ & $0.2228 \mathrm{E}-21$ & 1.022 & 1.025 & 0.397 & 0.379 \\
\hline$P^{Q}$ & 21 & 3 & 21 & 1165.46065 & 1165.46071 & -0.06 & $0.2291 \mathrm{E}-21$ & $0.2234 \mathrm{E}-21$ & $0.2228 \mathrm{E}-21$ & 1.025 & 1.028 & 0.397 & 0.388 \\
\hline$P^{Q}$ & 22 & 3 & 22 & 1165.28715 & 1165.28695 & 0.20 & $0.2092 \mathrm{E}-21$ & $0.1952 \mathrm{E}-21$ & $0.1946 \mathrm{E}-21$ & 1.072 & 1.075 & 0.382 & 0.409 \\
\hline$P^{Q}$ & 22 & 3 & 22 & 1165.29345 & 1165.29366 & -0.21 & $0.2023 \mathrm{E}-21$ & $0.1952 \mathrm{E}-21$ & $0.1946 \mathrm{E}-21$ & 1.037 & 1.040 & 0.382 & 0.369 \\
\hline$P^{Q}$ & 23 & 3 & 23 & 1165.11345 & 1165.11313 & 0.32 & $0.1797 \mathrm{E}-21$ & $0.1687 \mathrm{E}-21$ & $0.1682 \mathrm{E}-21$ & 1.065 & 1.068 & 0.360 & 0.367 \\
\hline$P^{Q}$ & 23 & 3 & 23 & 1165.10495 & 1165.10515 & -0.20 & $0.1793 \mathrm{E}-21$ & $0.1687 E-21$ & $0.1682 \mathrm{E}-21$ & 1.063 & 1.066 & 0.360 & 0.362 \\
\hline$P^{Q}$ & 24 & 3 & 24 & 1164.91515 & 1164.91528 & -0.13 & $0.1503 E-21$ & $0.1444 \mathrm{E}-21$ & $0.1439 \mathrm{E}-21$ & 1.041 & 1.044 & 0.335 & 0.338 \\
\hline$P^{Q}$ & 24 & 3 & 24 & 1164.92445 & 1164.92472 & -0.27 & $0.1542 \mathrm{E}-21$ & $0.1444 \mathrm{E}-21$ & $0.1439 \mathrm{E}-21$ & 1.068 & 1.071 & 0.335 & 0.349 \\
\hline
\end{tabular}


Table 3 : Vibrational dipole moment squared and Herman-Wallis coefficients (in $10^{-2}$ ) for the $v_{6}$ band of ${ }^{12} \mathrm{CH}_{3} \mathrm{~F}$ and average ratios between the measurements and the semiempirical calculation using Herman-Wallis coefficients

\begin{tabular}{cccccc}
\hline & & & \multicolumn{3}{c}{ This work * } \\
\cline { 4 - 6 } & Ref. [18] & This work & $P^{Q}$ & $R^{Q}$ & $\begin{array}{c}\text { Others } \\
\text { sub-branches }\end{array}$ \\
\hline$R_{0}{ }^{2} \times 10^{2}\left(\right.$ in D $\left.^{2}\right)$ & 2.835 & 2.8131 & 2.9132 & 2.8621 & 2.8483 \\
$\alpha \times 10^{2}$ & -3.94 & -3.96 & 0 & 0 & -3.87 \\
$\beta \times 10^{2}$ & 1.84 & 2.76 & 3.86 & 2.12 & 3.02 \\
$\gamma \times 10^{2}$ & 0.137 & 0.138 & 0 & 0 & 0.149 \\
\hline$\langle$ Obs/calc $>$ & $0.965(103)$ & $1.003(69)$ & \multicolumn{3}{c}{$1.000(53)$} \\
\hline
\end{tabular}

Note: $O b s$ stands for our measurements and calc for the calculations using the three different sets of parameters $\left(R_{0}^{2}, \alpha, \beta\right.$ and $\left.\gamma\right)$ from Ref. [18], this work and this work* (see text). 
Table 4: Parameters $a_{J}^{0}$ and $a_{J}^{2}$ (in $\mathrm{cm}^{-1} \cdot \mathrm{atm}^{-1}$ at $296 \mathrm{~K}$ ) retrieved for each set of self-broadening coefficients with same value of $J$. The second column of each parameter is used as substitutable smoothed or extrapolated values. Digits between parentheses represent $1 \mathrm{SD}$ (in the unit of the last digit).

\begin{tabular}{|c|c|c|c|c|}
\hline$J$ & $a_{J}^{0}$ & & $a_{J}^{2}$ & \\
\hline 0 & $0.647(3)$ & & $0.0^{*}$ & \\
\hline 1 & $0.567(7)$ & & $-0.1520(122)$ & \\
\hline 2 & $0.475(27)$ & & $-0.0210(26)^{\prime}$ & \\
\hline 3 & $0.455(10)$ & & $-0.0125(11)$ & \\
\hline 4 & $0.442(9)$ & & $-0.0079(11)$ & \\
\hline 5 & $0.447(6)$ & & $-0.0072(5)$ & \\
\hline 6 & $0.467(5)$ & & $-0.0048(4)$ & \\
\hline 7 & $0.479(7)$ & & $-0.0034(3)$ & \\
\hline 8 & $0.504(3)$ & & $-0.0027(3)$ & \\
\hline 9 & $0.526(4)$ & & $-0.0028(2)$ & \\
\hline 10 & $0.543(4)$ & & $-0.0026(2)$ & \\
\hline 11 & $0.555(6)$ & & $-0.0020(2)$ & \\
\hline 12 & $0.563(7)$ & & $-0.0018(2)$ & \\
\hline 13 & $0.553(6)$ & & $-0.0013(2)$ & \\
\hline 14 & $0.554(9)$ & & $-0.0012(2)$ & \\
\hline 15 & $0.532(7)$ & & $-0.00074(21)$ & \\
\hline 16 & $0.519(8)$ & & $-0.00071(20)$ & \\
\hline 17 & $0.508(8)$ & & $-0.00078(19)$ & \\
\hline 18 & $0.480(7)$ & & $-0.00053(14)$ & \\
\hline 19 & $0.455(4)$ & & $-0.00018(20)$ & -0.00038 \\
\hline 20 & $0.433(6)$ & & $-0.00039(11)$ & -0.00036 \\
\hline 21 & $0.400(5)$ & & $-0.00026(20)$ & -0.00034 \\
\hline 22 & $0.385(7)$ & & $-0.00040(20)$ & -0.00032 \\
\hline 23 & $0.363(7)$ & & $-0.00044(17)$ & -0.00030 \\
\hline 24 & $0.338(5)$ & & $-0.00034(24)$ & -0.00028 \\
\hline 25 & $0.308(8)$ & & $-0.00026(40)$ & -0.00026 \\
\hline 26 & $0.294(8)$ & & $-0.00022(28)$ & -0.00024 \\
\hline 27 & $0.271(8)$ & & $-0.00023(46)$ & -0.00022 \\
\hline 28 & $0.244(7)$ & & $-0.00023(26)$ & -0.00020 \\
\hline 29 & $0.227(7)$ & & $-0.00050(40)$ & -0.00020 \\
\hline 30 & $0.204(7)$ & & & -0.00020 \\
\hline 31 & $0.195(7)$ & & & -0.00020 \\
\hline 32 & $0.178(5)$ & & & -0.00020 \\
\hline 33 & $0.178(5)$ & 0.170 & & -0.00020 \\
\hline 34 & $0.178(9)$ & 0.165 & & -0.00020 \\
\hline 35 & $0.175(5)$ & 0.160 & & -0.00020 \\
\hline 36 & $0.166(8)$ & 0.155 & & -0.00020 \\
\hline 37 & & 0.150 & & -0.00020 \\
\hline 38 & & 0.145 & & -0.00020 \\
\hline 39 & & 0.140 & & -0.00020 \\
\hline 40 & & 0.135 & & -0.00020 \\
\hline 41 & & 0.130 & & -0.00020 \\
\hline
\end{tabular}


Note: ${ }^{*}$ The value for a $a_{J=0}^{2}$ has been fixed to 0 . 
Table 5: Sample of the line list generated in this work. The whole line list is available as supplementary material.

\begin{tabular}{|c|c|c|c|c|c|c|c|}
\hline \multicolumn{3}{|c|}{$\begin{array}{l}\text { Assignment } \\
J \quad K\end{array}$} & \multirow{2}{*}{$\begin{array}{c}\text { Line } \\
\text { position }\end{array}$} & \multirow{2}{*}{$\begin{array}{c}\text { Line } \\
\text { intensity }\end{array}$} & \multicolumn{2}{|c|}{$\begin{array}{l}\text { Self- and } \mathrm{N}_{2^{-}} \\
\text {broadening coefficients }\end{array}$} & \multirow{2}{*}{$\begin{array}{c}\begin{array}{c}\text { Energy of the } \\
\text { lower state }\end{array} \\
462.5300\end{array}$} \\
\hline $\mathrm{PP}$ & 11 & 9 & & & 0.377 & 0.111 & \\
\hline $\mathrm{RP}$ & 37 & 0 & 1116.24161 & $6.451 E-23$ & 0.150 & 0.096 & 1193.6500 \\
\hline $\mathrm{PP}$ & 34 & 1 & 1116.34611 & $6.894 E-23$ & 0.165 & 0.097 & 1015.1000 \\
\hline PP & 31 & 2 & 1116.57294 & $1.300 E-22$ & 0.194 & 0.098 & 860.2600 \\
\hline $\mathrm{PP}$ & 28 & 3 & 1116.78049 & $2.159 \mathrm{E}-22$ & 0.242 & 0.099 & 729.1900 \\
\hline $\mathrm{PP}$ & 28 & 3 & 1116.79552 & $2.159 E-22$ & 0.242 & 0.099 & 729.1900 \\
\hline $\mathrm{PP}$ & 25 & 4 & 1116.99005 & $3.158 E-22$ & 0.304 & 0.100 & 621.9300 \\
\hline $\mathrm{PP}$ & 22 & 5 & 1117.17888 & $4.061 E-22$ & 0.377 & 0.102 & 538.5200 \\
\hline PP & 19 & 6 & 1117.35365 & $9.182 \mathrm{E}-22$ & 0.441 & 0.104 & 478.9800 \\
\hline $\mathrm{PP}$ & 16 & 7 & 1117.51336 & $4.562 \mathrm{E}-22$ & 0.484 & 0.107 & 443.3500 \\
\hline $\mathrm{PP}$ & 13 & 8 & 1117.65686 & $3.993 E-22$ & 0.470 & 0.110 & 431.6300 \\
\hline $\mathrm{PP}$ & 10 & 9 & 1117.78279 & $6.198 E-22$ & 0.349 & 0.112 & 443.8200 \\
\hline $\mathrm{RP}$ & 36 & 0 & 1118.19138 & $8.249 E-23$ & 0.155 & 0.096 & 1131.0200 \\
\hline $\mathrm{PP}$ & 33 & 1 & 1118.28205 & $8.574 E-23$ & 0.170 & 0.097 & 957.4900 \\
\hline $\mathrm{PP}$ & 30 & 2 & 1118.49032 & $1.571 \mathrm{E}-22$ & 0.203 & 0.098 & 807.6900 \\
\hline $\mathrm{PP}$ & 27 & 3 & 1118.67972 & $2.537 E-22$ & 0.269 & 0.099 & 681.6700 \\
\hline $\mathrm{PP}$ & 27 & 3 & 1118.69267 & $2.537 E-22$ & 0.269 & 0.099 & 681.6700 \\
\hline $\mathrm{PP}$ & 24 & 4 & 1118.86859 & $3.604 E-22$ & 0.334 & 0.101 & 579.4700 \\
\hline $\mathrm{PP}$ & 21 & 5 & 1119.03718 & $4.501 E-22$ & 0.392 & 0.103 & 501.1400 \\
\hline $\mathrm{PP}$ & 18 & 6 & 1119.19114 & $9.880 \mathrm{E}-22$ & 0.461 & 0.106 & 446.6900 \\
\hline $\mathrm{PP}$ & 15 & 7 & 1119.32944 & $4.768 E-22$ & 0.496 & 0.109 & 416.1500 \\
\hline $\mathrm{PP}$ & 12 & 8 & 1119.45092 & $4.058 E-22$ & 0.448 & 0.111 & 409.5300 \\
\hline $\mathrm{PP}$ & 9 & 9 & 1119.55419 & $6.156 \mathrm{E}-22$ & 0.315 & 0.113 & 426.8200 \\
\hline $\mathrm{RP}$ & 35 & 0 & 1120.13474 & $1.045 E-22$ & 0.160 & 0.097 & 1070.0700 \\
\hline PP & 32 & 1 & 1120.21161 & $1.056 \mathrm{E}-22$ & 0.178 & 0.098 & 901.5600 \\
\hline $\mathrm{PP}$ & 29 & 2 & 1120.40116 & $1.881 E-22$ & 0.226 & 0.099 & 756.8000 \\
\hline $\mathrm{PP}$ & 26 & 3 & 1120.57215 & $2.951 E-22$ & 0.292 & 0.100 & 635.8400 \\
\hline $\mathrm{PP}$ & 26 & 3 & 1120.58324 & $2.951 E-22$ & 0.292 & 0.100 & 635.8400 \\
\hline $\mathrm{PP}$ & 23 & 4 & 1120.74026 & $4.072 E-22$ & 0.358 & 0.102 & 538.7100 \\
\hline $\mathrm{PP}$ & 20 & 5 & 1120.88847 & $4.937 E-22$ & 0.424 & 0.104 & 465.4500 \\
\hline
\end{tabular}

Note: 
Line positions (in $\mathrm{cm}^{-1}$ ) come from Ref. [24], line intensities (for pure $\mathrm{CH}_{3} \mathrm{~F}$ in cm.molecule ${ }^{-1}$ at 296K) are calculated with Eqs.

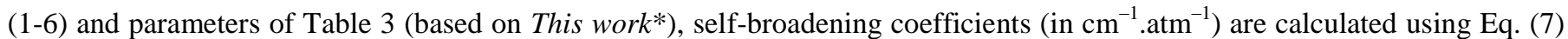
and parameters of Table 4 (substitutable smoothed values or extrapolation have been used when available). $\mathrm{N}_{2}$-broadening coefficients (in $\mathrm{cm}^{-1}$.atm ${ }^{-1}$ ) have been calculated using Eq. (7) and smoothed values of Table 2 of Ref. [10] obtained for $\mathrm{CH}_{3} \mathrm{Cl}$. The energies of the lower state (in $\mathrm{cm}^{-1}$ ) come from a calculation using parameters of Ref. [25]. In the assignment field the two first letters $(P, Q$ or $R)$ allow to identify the type of branch, first for $K$ and then for $J$. Then, the two rotational quantum numbers associated to the lower state, $J$ and $K$. 